\title{
Canal Transportation after Instrumentation Utilizing Different Endodontic Access Design; A Comparative Study with Micro-CT.
}

Travis Moore

Follow this and additional works at: https://researchrepository.wvu.edu/etd

\section{Recommended Citation}

Moore, Travis, "Canal Transportation after Instrumentation Utilizing Different Endodontic Access Design; A Comparative Study with Micro-CT." (2018). Graduate Theses, Dissertations, and Problem Reports. 8210. https://researchrepository.wvu.edu/etd/8210

This Thesis is protected by copyright and/or related rights. It has been brought to you by the The Research Repository @ WVU with permission from the rights-holder(s). You are free to use this Thesis in any way that is permitted by the copyright and related rights legislation that applies to your use. For other uses you must obtain permission from the rights-holder(s) directly, unless additional rights are indicated by a Creative Commons license in the record and/ or on the work itself. This Thesis has been accepted for inclusion in WVU Graduate Theses, Dissertations, and Problem Reports collection by an authorized administrator of The Research Repository @ WVU. For more information, please contact researchrepository@mail.wvu.edu. 


\title{
CANAL TRANSPORTATION AFTER INSTRUMENTATION UTILIZING DIFFERENT ENDODONTIC ACCESS DESIGN; A COMPARATIVE STUDY WITH MICRO-CT
}

\author{
Travis Moore, D.M.D. \\ Thesis submitted to the School of Dentistry of Robert C. Byrd Health Science Center \\ at West Virginia University \\ in partial fulfillment of the requirements \\ for the degree of \\ Masters of Science \\ in \\ Endodontics \\ Peter Ngan, DDS, Committee Chairperson \\ Bryan Weaver, DDS, MD \\ L. Keith Hildebrand, DDS, MS \\ M. Leigh Speer, DDS, MS \\ Department of Endodontics \\ Morgantown, West Virginia \\ 2018
}

Keywords: canal transportation, endodontic access, ProTaper NEXT, WaveOne Gold, microCT

Copyright 2017 Travis Moore D.M.D 


\begin{abstract}
CANAL TRANSPORTATION AFTER INTRUMENTATION UTILIZING DIFFERENT ENDODONTIC ACCESS DESIGN; A COMPARATIVE STUDY WITH MICRO-CT
\end{abstract}

\author{
Travis Moore, D.M.D.
}

$\underline{\text { Introduction }}$

Access cavity design is known to affect the efficiency of instrumentation. Canal transportation occurs primarily in the apical region and to the outside of curvature when dentin is removed in a single direction. The goal of all cleaning and shaping procedures is to preserve the original root canal anatomy while removing sufficient amounts of injured pulp tissue, microorganisms, toxins and instrumentation byproducts. It is understood that the desired shape of the finished root canal is a continuous tapering funnel from the coronal to the apex. The aim of this study is to construct detailed three-dimensional images of root canal systems and measure the change in canal anatomy based on varying the access cavity designs, using WaveOne Gold®(WOG) and ProTaper NEXT®(PTN) files.

\title{
Materials and Methods
}

All teeth used were 3D printed maxillary first molar teeth purchased from Dental Education Laboratories. One unaltered tooth was scanned with a SkyScan 1272 microCT to be used as the control when gathering pre-instrumentation measurements of root thickness. Images were transferred to corresponding Bruker imaging software platforms to evaluate the pre-instrumentation root thickness of the mesial buccal at 1.0, 3.0, 5.0mm's from the apex. Access stents for traditional and contracted access were then created using a microCT scan and 3D printer based on previously accessed molar teeth with traditional and contracted endodontic access. One hundred teeth were evenly divided into file and access combination groups A)WOG/Traditional access B)WOG/Contracted access C)PTN/Traditional access and D)PTN/Contracted access. Each tooth was then imaged and measured for root thickness of the mesial buccal at 1.0, 3.0, $5.0 \mathrm{~mm}$ 's from the apex manor identical to the pre-instrumentation measurement. After data collection a two-way ANOVA was carried out to assess how drill, access, and the interaction between drill and access affect canal transportation and centering ratio. Since canal transport at 3.0 and 5.0mm's have significant interaction p-values a Tukey HSD was done to see where the difference lies.

\section{$\underline{\text { Results }}$}

For canal transport at $1 \mathrm{~mm}$ from the root apex, contracted access design demonstrated higher canal transport than the traditional access type regardless of the file tested. At depths of $3 \mathrm{~mm}$ and $5 \mathrm{~mm}$, the traditional access type has a higher centering ratio than the contracted access type regardless of file 
utilized. At a depth of 5mm, the PTN file has a higher centering ratio than the WOG file regardless of access type.

\section{$\underline{\text { Conclusion }}$}

The current study did not show benefits for contracted endodontic cavity using either a continuously rotating or reciprocating file in the mesial buccal root of maxillary first molars. This access modality resulted in greater canal transportation at $1 \mathrm{~mm}, 3 \mathrm{~mm}$ and $5 \mathrm{~mm}$ from the apex. The ProTaper NEXT® file resulted in less canal transportation than WaveOne Gold ${ }^{\circledR}$ in all scenarios evaluated. However, the difference is only statistically significant at 3.0 and $5.0 \mathrm{~mm}$ 's from the apex when WaveOne Gold $®$ used with a contracted endodontic access. The greatest amount of canal transportation was seen with a combination of WaveOne Gold ${ }^{\circledR}$ and contracted access while the least amount of canal transportation was seen with a combination of ProTaper NEXT® and a traditional endodontic cavity. This difference was statistically significant. 


\section{DEDICATION}

To Jessica: Everything in my life that I have accomplished or will accomplish professionally will only be a small blip when I compare them to the great gift I have in you. God has already blessed me beyond my understanding when he introduced you into my life. I only hope that I can bring half the joy to your life that you bring to mine. You were willing to up root everything you knew and move eight hours away to allow me to pursue my dream. You never asked why or how or questioned if it was the right thing. You only lovingly encouraged and challenged me to be better. I know this without questions. I am better with you by my side.

To my Family: Dad, I am sure that I am not even aware of all the ways that you have sacrificed and fought to get me to this point. You have taught me to work hard for what I want, to ferociously peruse my goals, and most importantly to love the people around me. If I am no longer a dentist, but I am even a fraction of the man that you are I will consider my life a success. Lacy, you took on an impossible task of being a mother to a young boy. You have been a steady place in so many rocky situations. Thank you for your constant positive attitude. Mom, Candice, Punk and Chunk. I love you all. I hope to always be a positive example for you boys. I could not have made it to the point of completing my formal education without your support in so many ways.

To Dr. John Olmsted: How can I begin to express the role you have played in my life? You have mentored me and guided me through every step. We may not talk as often or as long as we might like but I have always known that you are a phone call away and that I have you in my corner. Knowing that has driven me to push harder and further than I would have otherwise. In all I do as an endodontist I think of you and hope that I make you proud. 


\section{ACKNOWLEDGMENTS}

Dr. M. Leigh Speer: I do not have the words to express my gratitude to you for allowing me to pursue this childhood dream. You saw something in me as a dental student and trusted me to enter a program and profession I know you hold dear. Thank you for you mentorship.

Dr. L. Keith Hildebrand: Thank you for your passion for WVU and endodontics. You have always been available for a consult or a joke whenever they were needed. I have truly benefited from both.

Dr. A. Tom Borgia: Thank you for your leadership. Over the past two years you have handled the responsibility of being Dean with grace while never forgetting your roots as a clinician. This has been a great inspiration as I push forward.

Dr. Patrick Petley: You have been a supporter and friend that I needed during this process. Thank you for your humble nature, willingness to do what is best for students and patients and teaching me to do the same.

Dr. Peter Nagn: Thank you for your advice and expertise as I have preserved through my first attempt at research.

Dr. Brian Weaver: Thank you for allowing an endodontic resident to come to the oral surgery department just to sit around and learn new things. I have learned a great deal from you and your whole department that I will carry with me always.

Mr. Christopher Waters: Thank you for your help planning and designing this project. You encouraged me to work ahead and watched over me every step along the way.

Dr. Jeffery Minchau: You have the unique ability to make everyone you meet feel like the most important person in the room. Thank you for the friendship and many laughs we have shared.

Dr. Kent McBride: I am constantly impressed by your ability to handle life's many task. You have modeled Christian leadership in all you do in ways I could only hope to imitate. Our relationship has been one of the great unexpected outcomes of my residency.

Dr. Spencer Stiles: I never cease to be blown away by the generosity that you and Bethanie have shown Jessica and I. You took strangers into your life and gave us a family while ours is far away. I don't have enough ways to say thank you from my family to yours.

Dr. Michael Tran: I have leaned on your calm presence and ability to never let the pressure of residency overwhelm you. You were a great co-resident for my time here and I wish you all the best life has to offer. 
Dr. Mehran Malakpour: Thank you for your willingness to help anyone at any time. Your presence in the resident room has been a joy and I cannot wait to see what your career has for you.

Dr. D. Cade Brawley: Your first year has made my second year residency a joy. You came in without ego and have taught me many things. It has been a great blessing to draw on your restorative expertise.

To the Residents that Came Before me: You have all created the program that we know now. There is a standard of clinical excellence and comradery that has been a large part of making this time in West Virginia feel like home.

Dr. Matthew Harper: "temporize and monitor for 6-8 weeks". These may be the words that define our professional relationship, but the personal friendship is what has made the far greater impact. Thank you for your friendship.

Ms. Sara McLaughlin: You have been an invaluable resource for all the residents wanting to do imaging research. The whole Animal Models and Imaging facility team have been a blast to work with.

Mr. James Ingles and Ms. Hannah Ludwick: Thank you both for your and help with the statistical analysis and help understanding the results.

Everyone in the WVU Endodontic Dept: The staff has been very important to education and experience. I have learned from each of you and will cherish the laughs and memories.

Thank you to all the faculty, staff, students, and residents who have become a part of my residency and making West Virginia University my home. Until country roads bring me back home I will always be proud to be a mountaineer! 


\section{TABLE OF CONTENTS}

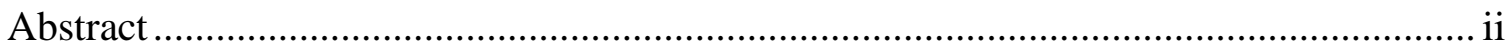

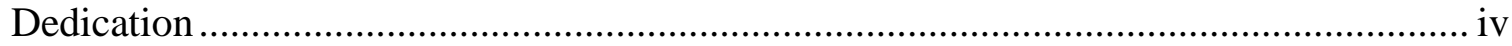

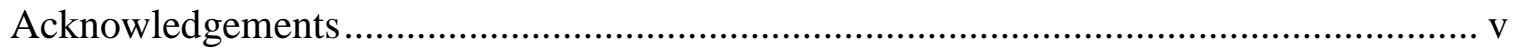

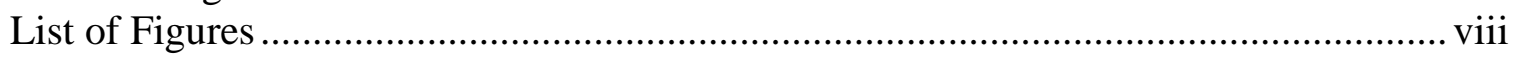

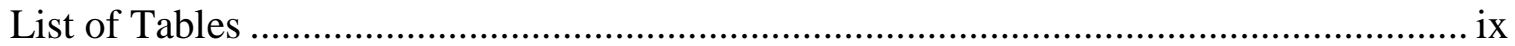

List of Symbols, Abbreviations, or Nomenclature .................................................... X

\section{CHAPTER 1}

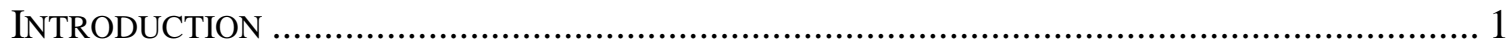

Statement of the Problem ......................................................................................... 6

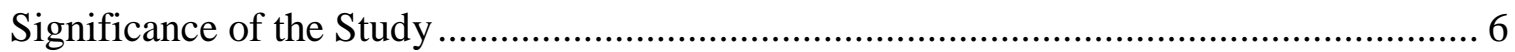

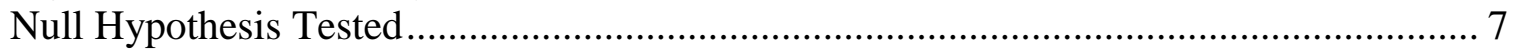

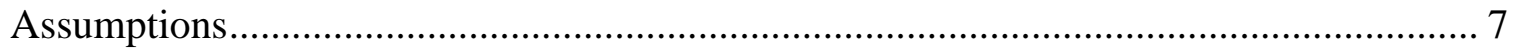

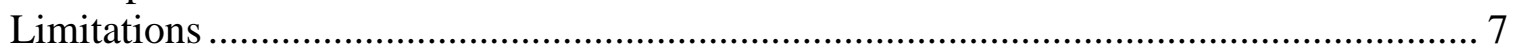

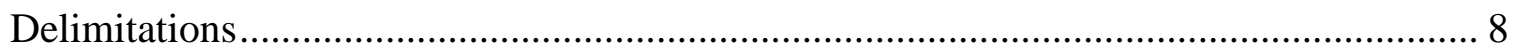

\section{CHAPTER 2}

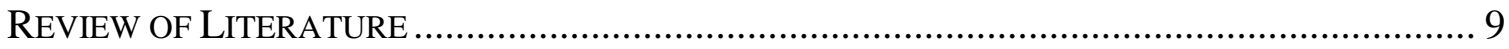

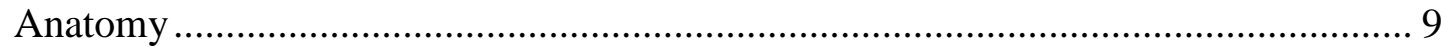

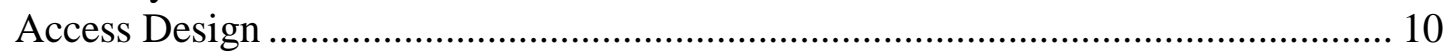

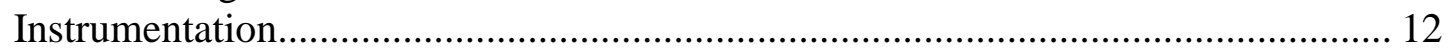

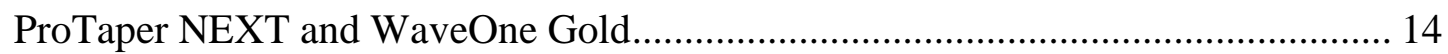

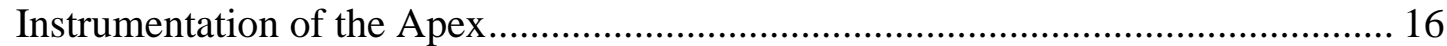

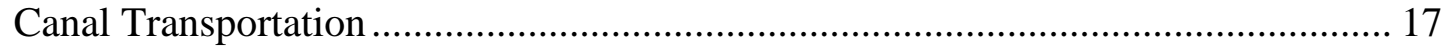

\section{CHAPTER 3}

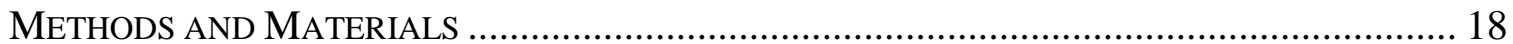

\section{CHAPTER 4}

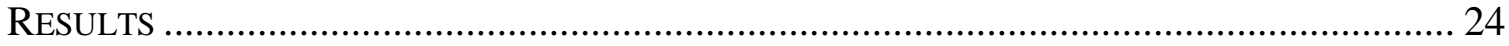

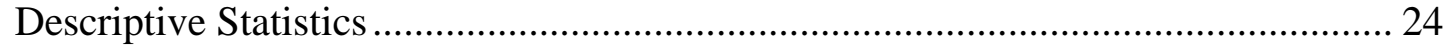

Analysis of Variance with Interaction Term ......................................................... 24

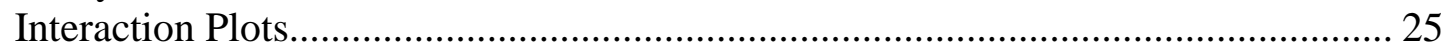

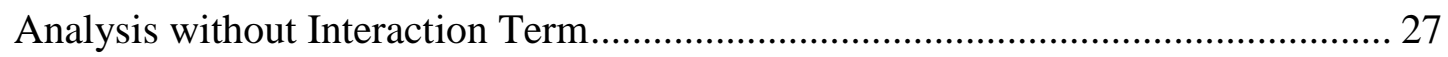

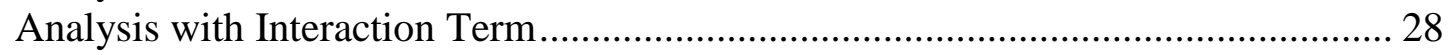

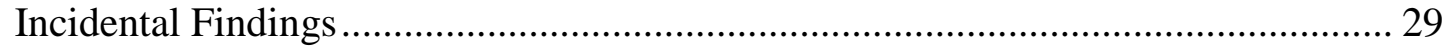

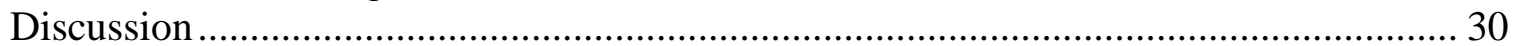

\section{CHAPTER 5}

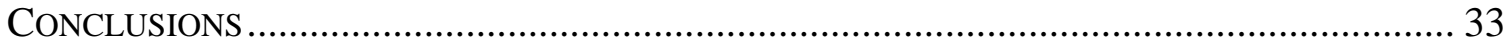

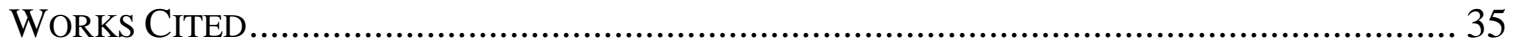




\section{List of Figures}

Figure 1. A micro-CT rendering of the MB root of True Tooth \#3 ........................................2

Figure 2. ProTaper NEXT X1-X5 Shape and Dimensions showing variable size and taper..................... 3

Figure 3. Schematic of ProTaper Universal vs. NEXT center of rotation, points of contact and envelope of

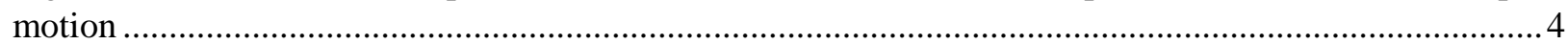

Figure 4. A schematic of the reciprocating motion and cross section of WaveOne Gold .............5

Figure 5. Schematic of WaveOne Gold variable taper at various lengths .................................6

Figure 6. Representative drawing of tooth sections showing how transportation, centering ratios, and largest diameter of the tooth were derived

Figure 7. Occlusal view of traditional endodontic cavity on the left and contracted endodontic cavity on the right.

Figure 8. Coronal view from the mesial of traditional access on the left and contracted access on the right stained with methylene blue to show contrast in size............................................... 21

Figure 9. 3D printed stint of traditional access on the left and contracted access on the right prior

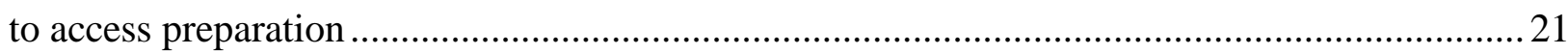

Figure 10. Proximal view from the mesial showing size 10 hand file at length...................... 22

Figure 11. Various interaction plots for potential variable interactions ................................ 25

Figure 12. MicroCT images of various access and file combination at $5 \mathrm{~mm}$.......................... 31 


\section{List of Tables}

Table 1. Means and Standard Deviations ............................................................................... 24

Table 2. Two-way ANOVA of file and access interaction .............................................................. 25

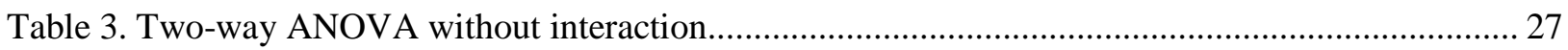

Table 4. Upper and Lower bounds for significant interaction variables................................. 28

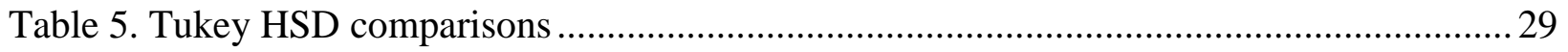


List of Symbols, Abbreviations, or Nomenclature

\author{
Mesial Buccal - MB \\ Mesial Palatal - MP \\ Second Mesial Buccal - MB2 \\ Millimeters - mm \\ Micrometers $-\mu \mathrm{m}$ \\ Traditionally endodontic cavities - TEC \\ Straight Line Access - SLA \\ Contracted endodontic cavity - CEC \\ Pericervical dentin - PCD \\ Cone beam computed tomography - CBCT \\ Nickel-Titanium - NiTi \\ ProTaper Universal - PTU \\ Wave One - WO \\ ProTaper NEXT® - PTN \\ Wave One Gold® - WOG \\ Master Apical Fie- MAF \\ International Organization for Standardization -ISO
}




\section{Chapter 1}

\section{$\underline{\text { Introduction }}$}

Root canal therapy can be broken down into four main components: coronal access, canal instrumentation, disinfection, and obturation of the root canal system. Care must be taken to ensure that all four parts are done adequately to remove inflamed/necrotic pulp tissue along with microorganisms and their toxic components. Proper endodontic access is frequently considered the most critical step in the endodontic procedure. Traditional endodontic access is believed to increase visibility, allow for greater condensation force during obturation and allow for safer, more efficient instrumentation $(1,2)$.

The American Association of Endodontists Glossary of Endodontic Terms defines transportation as "the removal of canal wall structure on the outside curve of the apical half of the canal due to the tendency of files to restore themselves to their original linear shape during canal preparation; may lead to ledge formation and possible canal perforation" (70).

As endodontic instrumentation techniques and materials continue to advance from hand files to the newer nickel titanium (NiTi) rotary file systems, removal of dentin from canal walls continues to be of interest (3). Canal transportation is greatest in the apical region towards the outside curvature with means values, based on studies by Peters reporting scores between 1.8 to $50 \mu \mathrm{m}$ of linear transportation $(4,5)$.

The maxillary first molar is the largest tooth in the adult dentition, with the most complex anatomy $(6,7)$. The mesiobuccal root of the maxillary first molar has generated more interest than any other root (8). Curved mesiobuccal root canals have, on average, shown the greatest amount of canal transportation during instrumentation (7). Maxillary first molars are also among the most common teeth to receive endodontic care (9).

Recently, Dental Education Laboratory®, introduced 3D printed acrylic teeth for the purpose of endodontic practice and education. All of the following information and images about True Tooth maxillary molar \#3 comes from the manufacturer's website. The maxillary molar is considered to have four canals with moderate pulp chamber calcification. "The MB2 canal has an apical terminus separate from the MB1 terminus, each of them communicating twice through 
mid-root isthmuses and ultimately bifurcating in their last 1-2mm's, with an apical diameter of $.22 \mathrm{~mm}$ " (figure 1). The MB2 root canal has a coronal impediment. The distalbuccal and palatal canals have size $.14 \mathrm{~mm}$ and $.39 \mathrm{~mm}$ apical diameters respectively along with apical branching and apical impediments.

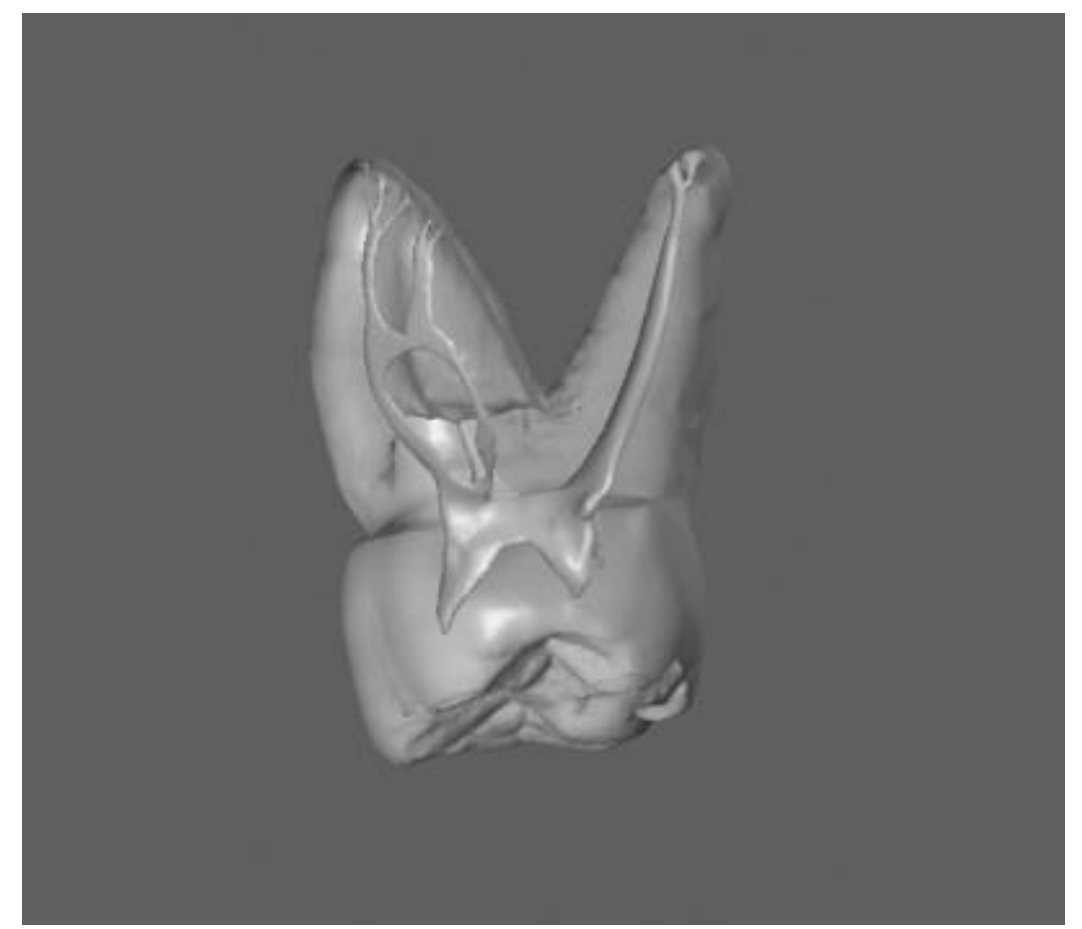

Figure 1. A micro CT rendering of the MB root of True Tooth \#3 (75).

Two endodontic files introduced into the market by Dentsply Sirona for instrumentation are theWaveOne Gold ${ }^{\circledR}$ and ProTaper NEXT®. Each of these two file systems offer a unique size of taper and path of rotation that are intended to provide faster, more efficient instrumentation. All of the following information and pictures about WaveOne Gold and ProTaper NEXT come from the DENTSPLY® website.

ProTaper Next rotary files utilize a variable taper (figure 2) and an off-centered, rectangular cross section. It differs from the original ProTaper design's concentric core that creates symmetric rotary motion as patented design's axis of rotation differs from the center of mass. The result is that only two points of the rectangular cross section touch the canal wall at a time (figure 3). This allows the ProTaper Next to have increased strength, lower torsional stress and 
decreased lateral compaction of debris. The file also differs from its predecessor in its use of MWire which decreases cyclic fatigue failure by $400 \%$. ProTaper Next manufacturer's claim that the patented asymmetric motion allows the clinician to produce a fully tapered canal with fewer files than ProTaner Universal or Gold.

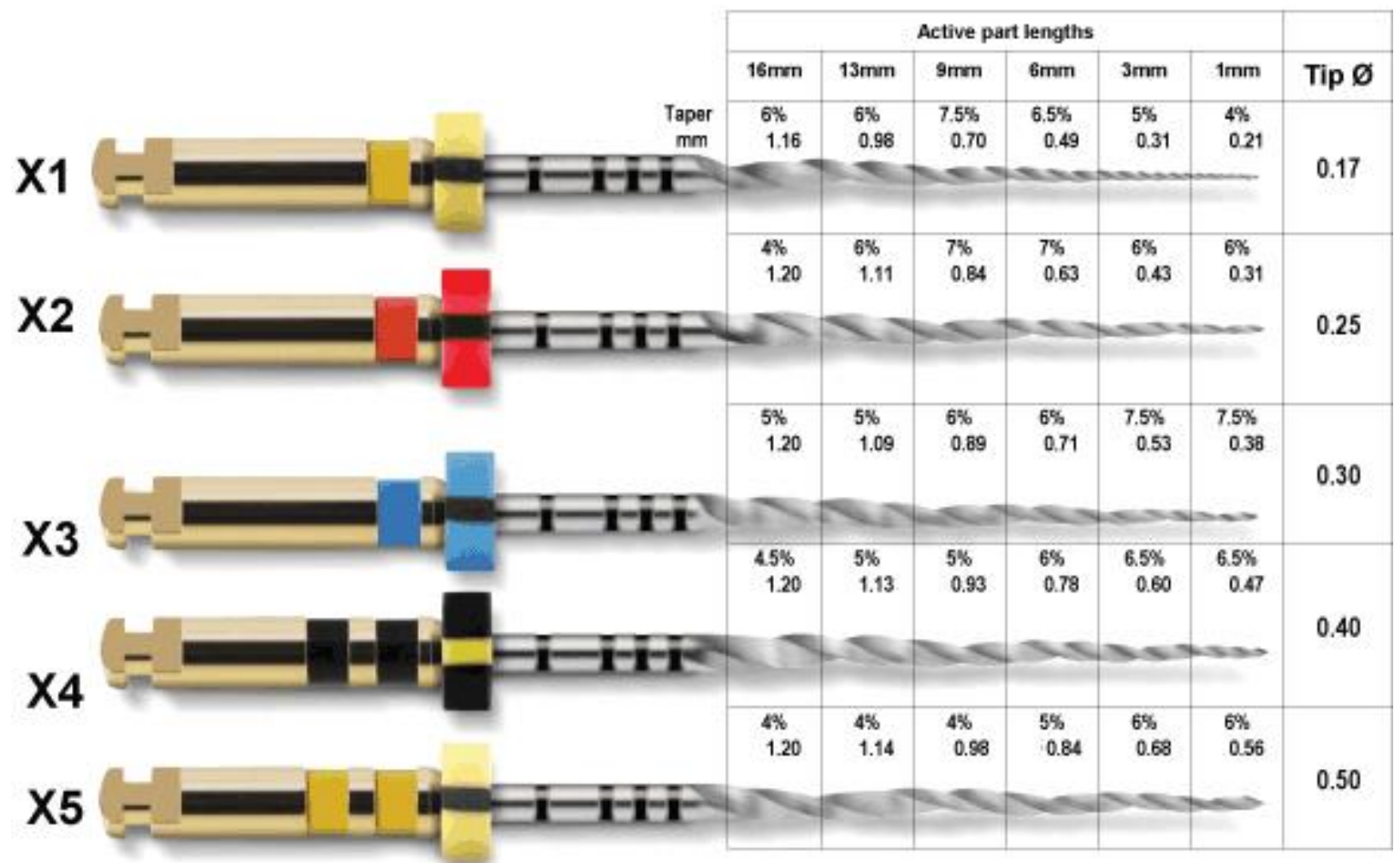

Figure 2. ProTaper NEXT X1-X5 Shape and Dimensions showing variable size and taper (74). 


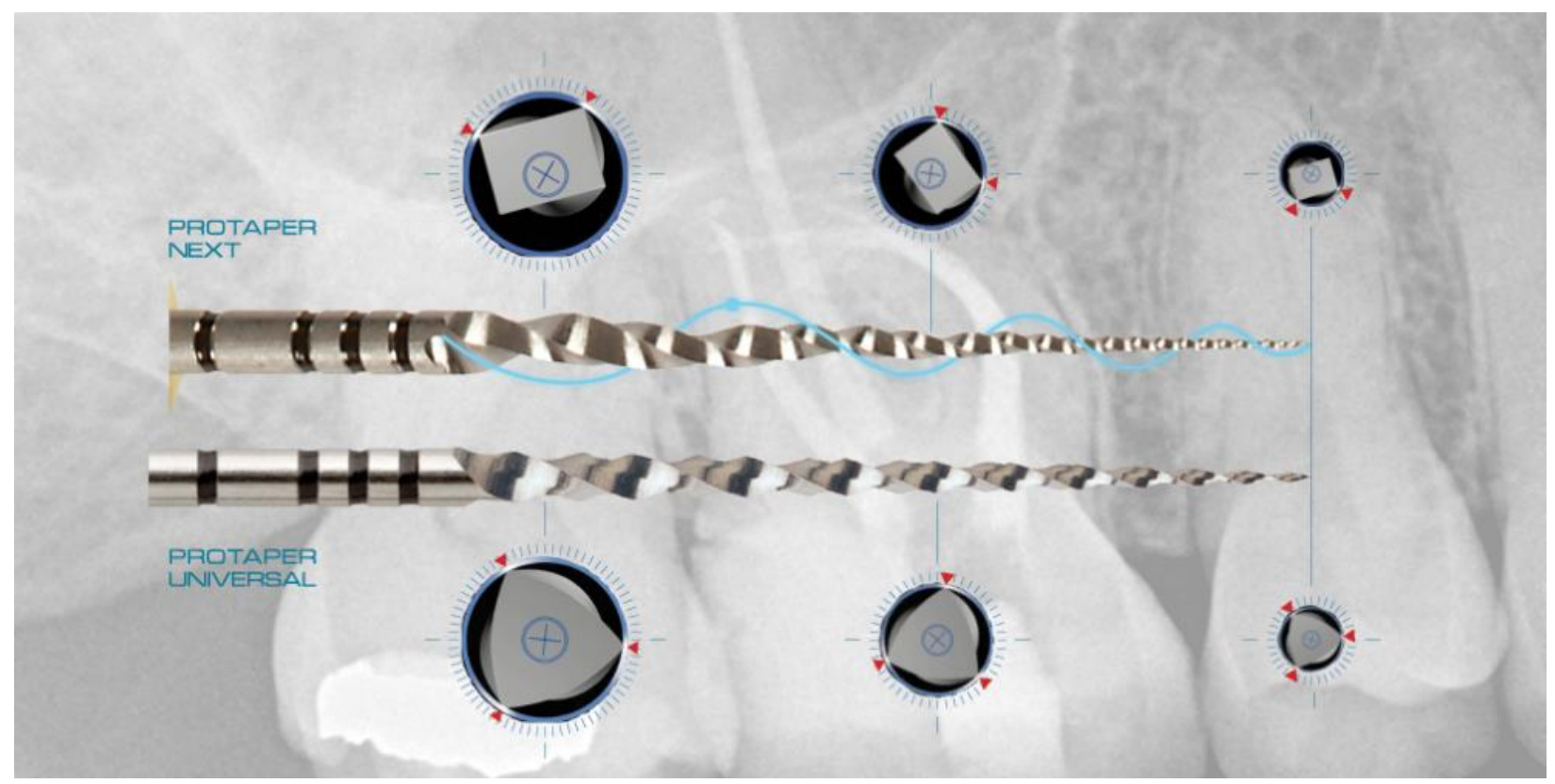

Figure 3. Schematic of ProTaper Universal vs. NEXT center of rotation, points of contact and envelope of motion (73).

WaveOne Gold provides a single-file shaping technique regardless of the length or the original size of the canal. According to the manufacturer, the Primary file is the only file required to fully prepare most canals. The files use the Gold-wire technology, the same as that of ProTaper Gold, along with a unique reciprocating movement and offset parallelogram-shaped cross-section (figure 4).

There are 4 files in the system termed Small (20/07), Primary (25/07), Medium (35/06), and Large (45/05). Each file has a fixed taper from D1 - D3 and a progressively decreasing percentage tapered design from D4 - D16 making it smaller than the original WaveOne. According to the manufacturer, the Primary WaveOne Gold file is $80 \%$ more flexible, 50\% more resistant to cyclic fatigue, and $23 \%$ more efficient, when compared to the original Primary WaveOne file. 


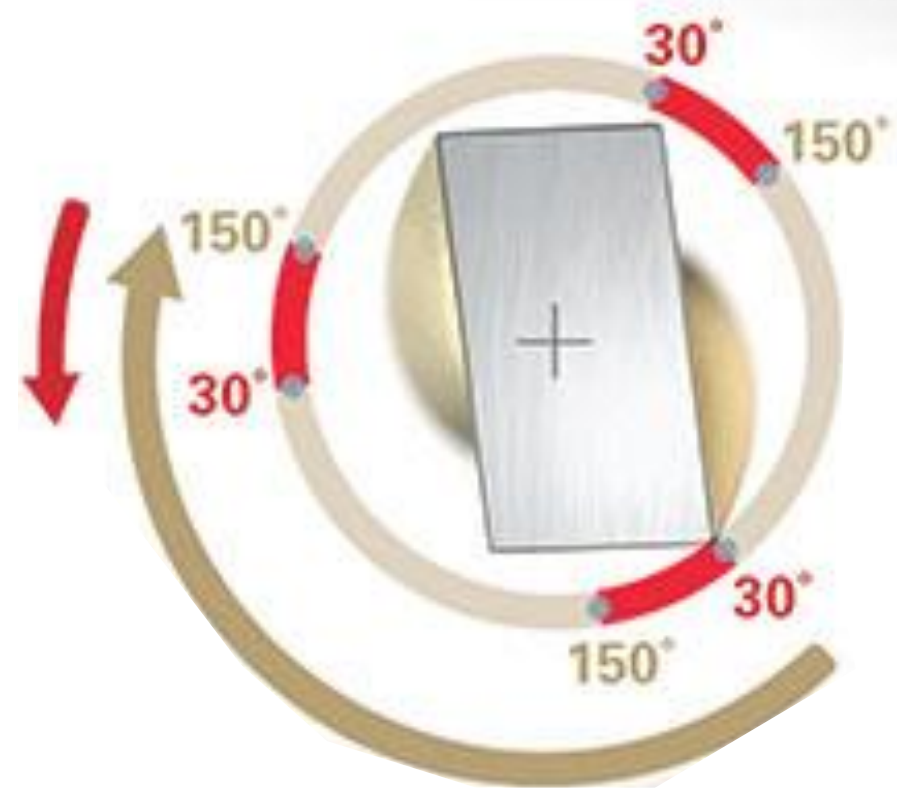

Figure 4. A schematic of the reciprocating motion and cross section of WaveOne Gold (72)

Several methods for evaluating the effect of endodontic instrumentation on root canal shape and size have been investigated. Previous studies have involved radiographic imaging and sectioning of teeth along various planes $(10,11)$. More recently, micro CT has become the primary means of evaluting instrumentaion efficency (11). The original micro CT studies produced images that were prone to errors, while the newer machines have made great strides in image resolution and minimzation of projection errors (12). Currently micro CT is useful because it allows for a non-destructive evaluation of the root canal space and its morphologic characteristics before and after instrumentation. This is a rapid and accurate technique with no irreversible damage to the sample tooth (13). 


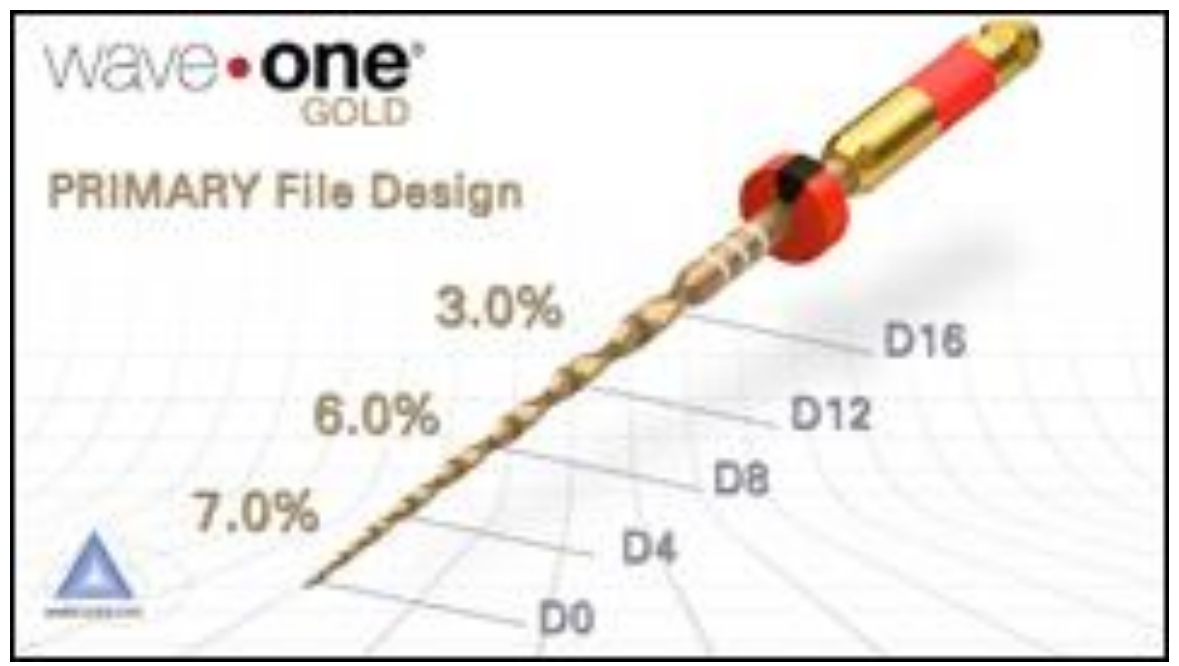

Figure 5. Schematic of WaveOne Gold variable taper at various lengths.(71)

\section{Statement of the Problem}

Canal transportation is an unavoidable consequence of endodontic instrumentation. It is also known that access design is an important part of the endodontic procedure. What is unknown is the effect of contracted endodontic accesses on the extent of canal transportation. At this time the majority of investigations of contracted endodontic access have focused on fracture strength and instrumentation efficiency (14-16). A second unknown is the results of direct comparison of WaveOne Gold and ProTaper NEXT inside of a curved canal of the mesial buccal root of a maxillary first molar with moderate to severe curvature.

The aim of this study is to construct a detailed 3D image of root canal morphology before and after instrumentation and measure the canal transportation at $1 \mathrm{~mm}, 5 \mathrm{~mm}$, and $7 \mathrm{~mm}$ from the apex using Dentsply Sirona WaveOne Gold and ProTaper NEXT files in the presence of a contracted endodontic access.

\section{Significance of the Study}

This study will give clinicians a greater understanding of the effect that access design has on the ability to maintain the original canal anatomy during endodontic instrumentation. It will 
also provide insight into the differences in commonly used file systems with similar cross sectional designs, but different rotational patterns. This may have an impact on the file system or the access design that each clinician chooses in a complex clinical setting.

\section{Null Hypothesis Tested}

There is no difference in canal transportation between traditional or contracted endodontic access; there is no difference between WaveOne Gold and ProTaper NEXT in terms of canal transportation utilizing various endodontic accesses.

\section{Assumptions}

- The mesiobuccal root of maxillary molars are concave and narrow with accentuated curvature.

- All True Tooth maxillary molar \#3 are the same

- Canal transportation is unavoidable regardless of the access or file used

- Canal transportation happens primarily towards the outside of the curvature regardless of the access or file used

- The greatest amount of canal transportation happens in the apical region

- Nickle-Titanium rotary files create less canal transportation than stainless steel hand files

- Micro CT is the most accurate and nondestructive way to determine instrumentation efficiency and canal transportation.

\section{Limitations}

- This is an in-vitro study using acrylic tooth models and may not correlate to clinical or invivo situations.

- The True Tooth is an acrylic model and not dentin. Instrumentation may react differently in a natural tooth.

- $\quad$ WaveOne Gold $®$ and ProTaper NEXT® have differing tapers along their working lengths 


\section{Delimitations}

- The use of micro CT is non destructive

- All teeth were accessed using a prefabricated stent

- All teeth were accessed and instrumented by a single operator 


\section{Chapter 2}

\section{$\underline{\text { Review of Literature }}$}

1. ANATOMY

The maxillary first molar is the largest human tooth by volume in the adult dentition and has been studied extensively. The majority of that literature focused on the mesial buccal (MB) root with particular attention given to the mesiopalatal (MP) or MB2 canal (17). The mesial buccal root volume is $0.53 \pm 0.32 \mathrm{~mm}^{3}$ which is larger than distobuccal and smaller than palatal roots (18). There remains debate as to the actual incidence of MP(MB2) canals, with reports ranging from 18 - 96.1\% (19). The great variance in this reporting is likely due to the evolution in methods used to evaluate root configuration. $(8,10,20,21)$. What can be agreed upon, however, is that with the addition of micro CT analysis and the operating microscope, the MP (MB2) canal is found to be present far more frequently than originally suggested. There also remains uncertainty about the percentage of MP (MB2) canals that can be located and instrumented (19). Baratto, in a clinical trial, found that MP (MB2) canals could only be negotiated up to the complete working length in $27.5 \%$ of cases (10). This is clinically relevant in that a micro CT study of root canal volume found when the MP (MB2) canal is left undiscovered and/or uninstrumented along with isthmus accompanying regions, it represents half the volume of the total mesiobuccal root canal system prior to instrumentation (22).

Contributing to the great variation of the MB root is the combined variability of canal isthmuses along with apical anatomy. As noted with the majority of roots, the most portals of exit and accessory foramina are in the last three millimeters of the root (21). The MB root primarily has one root canal entrance, with one main foramen, but accessory canals have been noted between 26.3 - $48 \%$ of the time. Accessory canals are present with greater frequency in the MB canal when compared to the MP canal $(21,23)$. Proper endodontic instrumentation and obturation are the clinician's recognition of the difference between physiologic foramen and anatomic foramen. The physiological foramen is sometimes called the apical constriction which is defined as the narrowest 
diameter of the canal located at the cementodentinal junction. The anatomic foramen is defined as being located at the terminus of the canal on the root surface. This would typically be considered the radiographic apex in traditional endodontic definitions. These two landmarks are separated by approximately 0.5 to $1 \mathrm{~mm}$ (24). Literature regarding the number of physiologic foramen also varies widely with reports ranging from $14-71.15 \%$ of teeth possessing two separate physiologic foramen $(19,24)$. The most common shape of the physiologic foramen is oval (24).

A macroscopic view of the mesiobuccal root of the maxillary first molar demonstrates it to be narrow in the mesiodistal dimension when compared to the broadness seen upon examination in the faciolingual dimension (19). Schneider defined root curvature as "the acute angle between the long axis of the canal and a line from the apical foramen to the point of initial curvature". Based on this definition, one study, which utilized micro CT coupled with mathematical modeling software, found that mean curvatures were found to be the highest in the MB canal with values between $0.22 \mathrm{~mm}^{-1}$ $0.38 \mathrm{~mm}^{-1}$. Overall, the greatest amount of curvature was found to be in the apical one third of the canal (25). This further contributes to the complexity of the apical portion of the root canal system and the need for safe, non-destructive chemomechanical preparation. Understanding the morphology of the coronal pulp space is also important in avoiding procedural errors such as perforation or gouging during endodontic access. The distance from cusp tip to coronal chamber ceiling, along with the distance from coronal chamber floor to furcation, are important land marks for correct endodontic access. Radiographic evaluation of 100 minimally carious or minimally restored teeth determined the distance from cusp tip to coronal chamber ceiling to be roughly $5.77 \mathrm{~mm}$, and the distance from coronal chamber floor to furcation to be roughly $3 \mathrm{~mm}$ (26).

\section{ACCESS DESIGN}

Traditional endodontic cavities (TEC) or preparations taught in dental schools, focus on complete de-roofing of the pulp chamber. This design is utilized to minimize file deflection, facilitate straight line access (SLA) to the apical one third of the canal 
while at the same time allowing for greater condensation pressure during obturation techniques $(27,28)$. This is usually accomplished through the use of a variety of rotary instruments including tapered fissure and diamond burs, Gates Glidden drills, Peeso reamers, or a variety of other instruments operators have used to remove coronal tooth structure (28). The traditional access is largely guided by the various laws of symmetry, laws of color change and laws of orifice location reported by Kransner and Rankow (29). To achieve this commonly taught access shape, removal of healthy coronal tooth structure, as well as any and all dentin ledges that obscure the entrance into the canal orifice, is eliminated to create smooth, slightly divergent walls to allow direct access to the apical one third of each canal $(27,30)$.

It is commonly accepted that the TEC is the ideal access shape based on the assumption that it will enhance the practitioner's effectiveness and efficiency during all endodontic procedures. A supportive reason for the TEC is the improved MP canal detection and finding that the rate of detection of MP canals more than doubled when the larger, cuboidal access was used (19). It has also been found that coronal interferences hinder the clinician's ability to determine the true apical diameter as well accurately measure length (28). Where interferences were present, canal lengths changed varying from the extremes of 0.05 to $0.60 \mathrm{~mm}$ before and after creation of $\operatorname{SLA}(28,31)$. Proponents of traditional accesses also point to the reduced amount of apically extruded debris when straight line access and cervical pre-flaring are established (32).

Some authors claim that traditional endodontic cavity preparation is overly focused on the desire of the clinician to create ease of accessibility to the orifice, is detrimental to the structural integrity of the tooth and wholly inappropriate from a restorative standpoint $(33,34)$. They further claim that this access design is contradictory to concepts of minimally invasive dentistry by showing a lack of consideration for original tissue structure (35). The contracted endodontic cavity (CEC) as proposed by Clark and Khademi, is far superior to the TEC in its ability to preserve the roughly $4 \mathrm{~mm}$ above and below the crestal bone; termed the pericervical dentin (PCD). Retaining as much as possible of the PCD avoids the need for post placement and full coverage restoration and decreases cuspal deflection of endodonticlly treated teeth (34). The goal 
of the CEC is to preserve a small piece of roof around the circumference of the pulp chamber referred to act as a "soffit" while producing a narrow access that constricts from the level of the alveolar crest until it steps out of the soffit while still allowing for full length instrumentation and obturation of any root canal space (14). These accesses are now more viable options than in previous generations with the use of CBCT allowing for the smallest possible outline of access to be planned. In addition, the use of the operating microscope promotes preservation of root canal dentin $(33,36)$.

The stated goal of minimally invasive dentistry is to "minimize loss of tooth structure; particularly, the PCD. This will reduce cuspal deflection and increase fracture resistance and thus should be preferred". However, the average load required for fracture of maxillary molars treated with CEC did not show a significant improvement over those treated with TEC (15). This is in disagreement with a similar study that found a roughly 2.5 times increase in the facture resistance of mandibular molars and premolars when utilizing CEC (36).

Arguments against the contracted endodontic cavity are primarily focused on instrumentation efficiency and time required to locate and treat the complete root canal space. During maxillary molar root canal treatment with CEC, instrumentation only modified $49-50 \%$ and $38 \%$ of buccal and palatal canal walls respectively (15). These findings were similar to those found in mandibular molars where CEC resulted in a statistically significant higher amount of untouched walls in distal canals, and in particularly, in the apical one third (36). When studying the use of CEC in endodontic retreatment, Niemi found that significantly more time was required when using CEC, but there was greater gutta percha removal (37).

\section{INSTRUMENTATION}

Critical to the success of non-surgical endodontic therapy is the mechanical instrumentation of the infected root canal space. While combined mechanical instrumentation and chemical irrigation in the form of sodium hypochlorite resulted in greater than $90 \%$ reduction of bacteria, instrumentation alone is known to be effective in 
reducing the number of bacteria present in infected root canals (38). Considerations of canal length, taper, and the horizontal dimension of canal instrumentation are all designed to create a canal preparation with continuous tapers from apical to coronal portions of the root while respecting the original canal shape $(3,39)$. Careful instrumentation with regards to the original canal configuration results in a canal preparation that has been cleaned and shaped on all sides, providing the best chance for a tight canal/dentin interface following obturation. Improper technique causes difficulty regardless of filling material or procedure $(4,40)$.

While the importance of enlarging the size of the original canal is without dispute, the question remains "how large is large enough?" Some authors claim that larger canals are more advantageous because they incorporate more canal irregularities and show greater bacterial reduction $(31,38)$. Increased apical preparation sizes allow for a greater amount of irrigant to be delivered to the apical region of the tooth (41). This method of instrumentation is not in accordance with the principle of minimally invasive dentistry (35).

There is currently no system or instrumentation technique that perfectly accomplishes all the desired goals of instrumentation and disinfection. Because of complex anatomy of teeth, along with the tendency of files to straighten inside canals; it is impossible to remove all microorganisms or create a final shape that is truly funnel form from apex to orifice $(4,20,21)$. Another unintended but yet unavoidable consequence of root canal instrumentation is the production of dentinal chips. These remnants of pulp, microorganisms and irrigation solutions can be transported beyond the apex of the canal and into the periradicular tissues (32). There is no file system now available that does not result in some extrusion of root canal by-products, and it is the introduction of these by-products into the periaical tissues that is thought to be a major cause of postoperative pain and flare-up (42).

There have been several different theories on the best way to accomplish all the goals of instrumentation, with none accomplishing all of them. Prior to the introduction of nickel-titanium (NiTi) rotary files, cleaning and shaping was typically completed solely with the use of hand files in a step back manner from apex to orifice. In the past 
several years manufacturers and dentists have introduced files and techniques that are claimed to eliminate the need for hand files and rely exclusively on the use of NiTi rotary instruments. Although there is no significant difference between hand files and NiTi files in removing intracanal bacteria, NiTi rotary instrumentation has become the method of choice for most clinicians $(43,44)$. Currently the most common technique of instrumentation combines hand and NiTi files where the clinician will use hand files of smaller sizes to gauge and secure the canal prior to proceeding to rotatory $\mathrm{NiTi}$ instrumentation.

Nickel-Titanium files have gained in popularity due to their superiority in ability to remain centered in canals, maintain original canal anatomy, and decrease the operator's time for completion of the cleaning and shaping procedures (45). The greater flexibility of NiTi files is due to the elastic modulus and super elasticity of this metal alloy compared to stainless steel hand files (46). This flexibility allows NiTi files to maintain the original shape of the canal while staying centered in the canal being treated. Their use minimizes irregularities such as "zip" perforations and creation of ledges (47). NiTi files work in an Archemedes screw manner in which the flutes of the file are packed with debris and pulled up and out in a coronal direction in an effort to reduce compaction of debris on canal walls or through the apex $(32,43)$.

\section{PROTAPER NEXT AND WAVE ONE GOLD}

Currently, there is great interest in the movement away from the use of traditional, continuous rotary files with the center of rotation placed in the file's center of mass. Instead, reciprocating files, where the center rotation is offset from the center of the file, are being used. The reciprocating, as opposed to rotating motion files have the benefit of prolonged resistance to fatigue, decreased preparation time, and creation of smaller apical preparation sizes (48-50). The advantage of the offset design, is a decreased screwing effect and taper lock which may lead to instrument failure inside the canal (49). Current files produced by Dentsply Tulsa Dental ${ }^{\circledR}$ utilizing reciprocation and off set design include Wave One Gold® (WOG) and ProTaper NEXT® (PTN) respectively. 
WaveOne Gold® is the newest iteration of Dentsply's original WaveOne file and features a parallelogram cross section with two cutting edges. The files are manufactured with a proprietary "gold" heat treatment similar to ProTaper Gold®, all of which contribute to greater cyclic fatigue resistance of the WaveOne Gold when compared to the original WaveOne (51). ProTaper NEXT boasts a series of instruments with variable tapers and rectangular cross section similar to that of WOG. The offset design allows for a larger envelope of cutting motion than similarly sized files that do not rotate in an off center fashion (32). PTN is made out of M-Wire NiTi, a hybrid metal containing all three crystalline phases of martensite, R-phase, and austenite $(46,52)$. WaveOne Gold is intended to be a single file system. The "primary" WOG file is to be inserted into the canal and advanced in $3 \mathrm{~mm}$ increments, followed by irrigation and recapitulation until working length is reached. PTN is a serial file series consisting of 5 files (X1-X5) used in a straight to length fashion until the desired apical size is achieved. In the PTN system, each sequential file is effective and required for proper cleaning and shaping of the canal (45).

Given the originality, popularity and similar attributes to PTN and WOG, the original ProTaper Universal (PTU) and Wave One (WO) files are commonly used when comparing instrumentation effectiveness. While the PTU system resulted in more actively instrumented canal wall area, the centering ability of the files was found to be similar with PTN which resulted in less canal transportation (53). PTN has also been found to be more resistant to cyclic fatigue in curved canals than PTU, particularly in the apical region $(47,54)$. The effect of any file on the apical one third of the root canal system is of particular interest. In direct comparison, PTN was found to produce fewer dentinal cracks than both PTU and WO, while at the same time creating less apical extrusion of debris than WO $(55,56)$. This may or may not be clinically significant since there is no known difference in reports of post procedure pain among patients treated with either PTN and WO (42). 


\section{INSTRUMENTATION OF THE APEX}

Adequate cleaning, shaping and obturation of the apical region of the tooth is essential for the success of root canal therapy (40). Accomplishment of this goal may prove to be difficult because the apical one third of any canal will have the greatest amount of root curvature (25). The goals of "apical endodontics" are ideally accomplished when there is an apical seat, usually created via the use of increasing tip sized instruments taken to working length $(22,31)$. Care must be taken to establish and maintain working length at or as close to the minor constriction for safe and effective chemo-mechanical instrumentation of the apical region (56).

A great deal of concern and debate regarding the apical region of the root canal space has been the discussion of what size diameter file should be the master apical file (MAF). Put another way, how big should we make apex? Some investigators have suggested a fixed minimum MAF for all canals; others contend that taper is more important than tip size. Currently an acceptable standardized size has not been determined, most likely due to the great variability in apical anatomy $(39,57)$.

Weine postulated that the MAF should be three ISO (International Organization for Standardization) sizes larger than the size of the first file to bind at length. For example, after straight line access is established, when an ISO size 15 stainless steel hand file is able to fit passively to length, the MAF in that canal should be worked to an ISO size 30. This method has fallen out of favor as subsequent studies has shown that the first file to bind is an unreliable measure of canal size and that the uninstrumented canal is usually larger than would be measured with a hand file $(39,57,58)$.

As previously mentioned, irrigation with a solution capable of tissue dissolution and bacterial destruction is important in non-surgical endodontics. This is of particular significance in the apical region due to lateral and accessory canals that are not capable of being instrumented. Increases in either apical preparation size \#45 or taper up to ISO 0.08 , result in a mean increase of irrigates at the apex (59).

Bacterial reduction studies based on sequential apical size enlargement have not been consistent. Studies have yet to identify a MAF size that consistently yields negative 
culture results when sampled from the apex of infected teeth. Apical size enlargement has shown that there is a statistically significant reduction of bacterial mass up to six sizes larger than the first file to bind, with some authors suggesting that a minimum size 60 file is required to adequately prepare the apical $1 \mathrm{~mm}(44,60)$. This may or may not be clinically relevant since studies published prior to the advent of NiTi files consistently found greater healing rates when the MAF was kept as small as possible (57). These findings are consistent with more recent studies that show apical enlargement did not affect the healing of teeth with periapical lesions (61). Increasing the size of the apical preparation brings about risk of tooth fracture and may produce canal irregularities such as apical transportation which may not be in line with today's understanding of minimally invasive dentistry (18).

\section{CANAL TRANSPORTATION}

During canal preparation, procedural errors such as zipping, stripping, and ledging of the apex are common occurrences that result in poor cleaning and shaping, along with inadequate obturation of the root canal space (52). Some degree of transportation of the canal is unavoidable in modern endodontics. The greatest amount of transportation happens in the apical region of the root being treated $(5,48)$. The use of NiTi rotary files produces less apical transportation than hand files regardless of instrumentation technique. Still, $80 \%$ of micro CT studies show some measure of apical transportation $(40,48)$. Canal transportation taken as a whole is usually in the range of $100-200 \mu \mathrm{m}$, with PTN being measured anywhere form $77-195 \mu \mathrm{m}$ (52).

Transportation is even more pronounced in curved and narrow canals $(13,52)$. With our current understanding of the complexity, narrowness and curvature associated with canal apices it is understandable why the apical region is the most transported portion of the canal during endodontic mechanical instrumentation. Every endodontic file has a tendency to straighten inside canals when engaging dentin and as a result, the greatest amount of transportation happens at the expense of the outside of the canal curvature, resulting in a tear drop or hourglass shaped apex as opposed to the oval shape found pre-instrumentation $(4,40)$. This becomes important to the clinical success and 
failure of endodontics due to increased leakage that occurs when apical transportation is greater than $0.3 \mathrm{~mm}(40)$.

Apical transportation can be subdivided based on the degree of transportation and the intervention required to resolve it. Type I transportation is only a minor movement of the physiologic foramen and may be corrected by removing small amounts of dentin in the immediate coronal area to recreate the apical seat. Type II transportation is a moderate relocation of the physiologic foramen in which there is a large communication with the periapical tissues requiring the use of an apical barrier prior to obturation. Type III transportation is a severe movement of the physiologic foramen in which traditional obturation is no longer feasible and the tooth may require surgical intervention if it is to be retained (69).

\section{Chapter 3}

\section{$\underline{\text { Methods and Materials }}$}

All experimental teeth were purchased from Dental Education Laboratory (Santa Barbara CA, USA). One hundred teeth were randomly assigned into four groups of twenty-five. One group of teeth received treatment with traditional endodontic access and WaveOne Gold Primary. A second group was treated with traditional endodontic access and ProTaper NEXT up to a size X2. A third group was treated with contracted endodontic access and WaveOne Gold Primary. A second group was treated with contracted endodontic access and ProTaper NEXT up to a size $\mathrm{X} 2$.

Scanning of all teeth was conducted at The West Virginia University Animal Models and Imaging Facility. A SkyScan 1272 micro CT (Bruker, Aartselaar, Belgium) with an isotropic voxel size of $18 \mu \mathrm{m}$ was used to scan the teeth. The radiographic settings were $60 \mathrm{kVp}$ and 166 $\mu$ A. One unaltered tooth was individually mounted on the SkyScan mounting table modified with a putty matrix with the tooth mounted upright to the coronal height of contour to ensure repeatability of the orientation. 
Images of a single unaltered tooth obtained from the SkyScan 1272 micro CT were transferred to corresponding Bruker imaging software platforms Data Viewer, CTAn, and CTVol to evaluate the pre-instrumentation root thickness of the mesial buccal at 1.0, 3.0, 5.0 mm's from the apex. Cross sectional images at those corresponding distances from the apex were used for measurement.

The extent of canal transportation was determined by measuring the shortest distance from the edge of the un-instrumented canal to the edge of the external root surface to both the inside and outside of the canal curvature. The same measurements were taken after instrumentation for comparative purposes. Quantitative analysis was completed using the formula: (X1-X2) - (Y1-Y2). In this formula X1 represents the shortest distance from the outside of the curved root external surface to the border of the un-instrumented canal. Y1 represents the same landmarks on the inside of the curved root. Similarly X2 and Y2 are taken after instrumentation using the same landmarks of the corresponding $\mathrm{X}$ and $\mathrm{Y}$ variables. No canal transportation is indicated when a calculation using the canal transportation formula results in a score of zero (62).

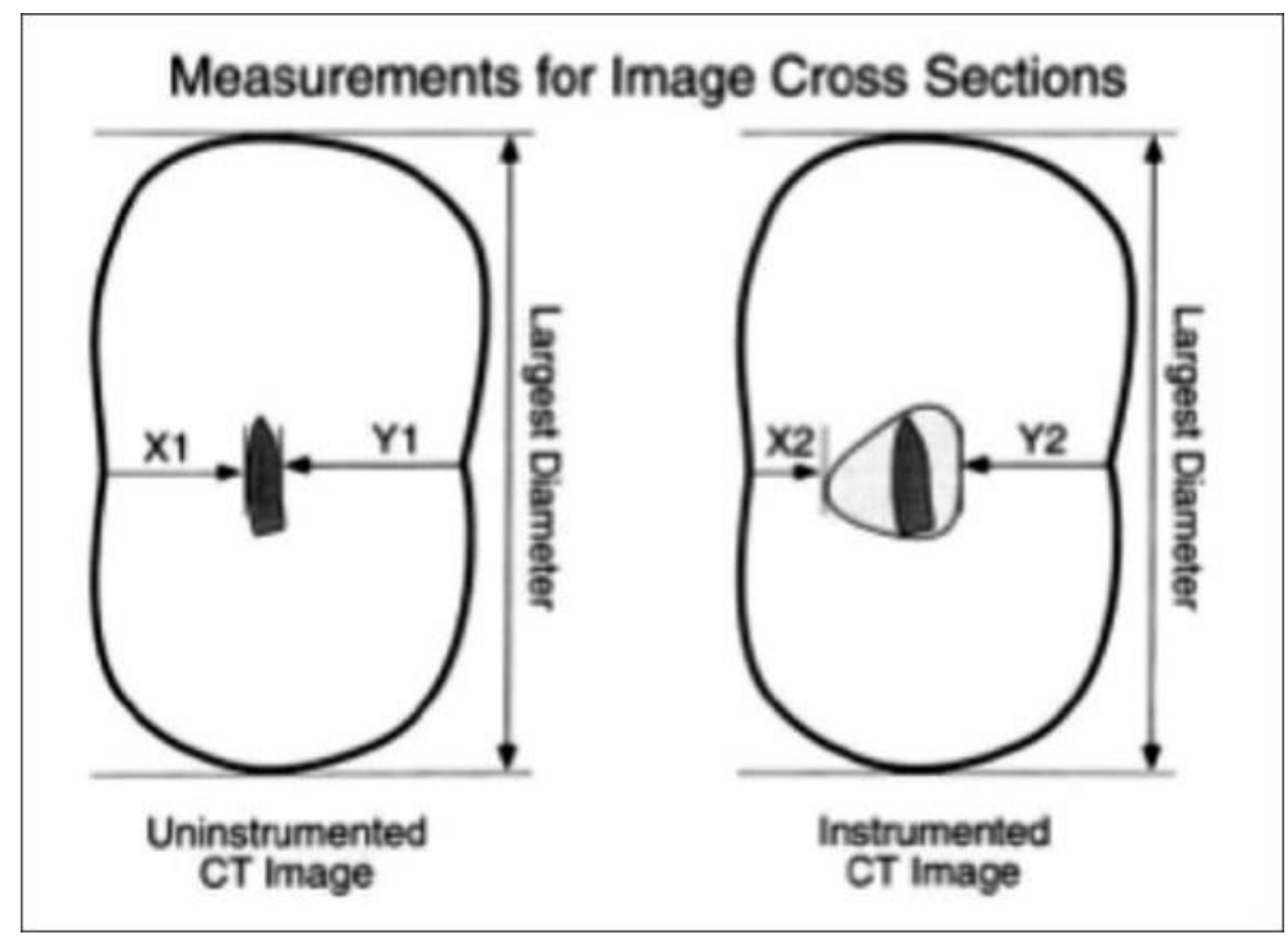


Figure 6. Representation of tooth before and after instrumentation showing how transportation, centering ratio, and largest diameter of the tooth were measured. Un-instrumented image on the left shows dark center area before instrumentation. Instrumented image on the right shows lighter area after instrumentation superimposed on top of original canal (62).

Centering ratio is a measure of an instrument's ability to stay centered in a canal. Using the same measurements for canal transportation, centering ratio was calculated using the ratio: (X1-X2) to (Y1-Y2). Ideal centering of the instrument would be indicated by a result of 1 (62). In the event that centering is not perfect, the smaller of the two numbers would be taken as the numerator.

One operator performed the endodontic access and mechanical shaping of all teeth to eliminate operator variation. The teeth initially were accessed with a 957 end cutting carbide bur (Brasseler USA, Savannah, GA, USA) in high speed handpiece with water coolant (Figures 7 \& 8). Both traditional and contracted access were guided via a 3D printed stent (figure 9) created after CBCT scan of True Tooth in accordance with previously reported stent creation by Connert in 2017 (63). Once in the chamber, Endo-Z bur (Dentsply, York, PA, USA) was used to smooth walls and create coronal flare. Canals were initially negotiated with a size $10 \mathrm{~K}$ file (Flexofile $\AA$, Dentsply, York, PA, USA).

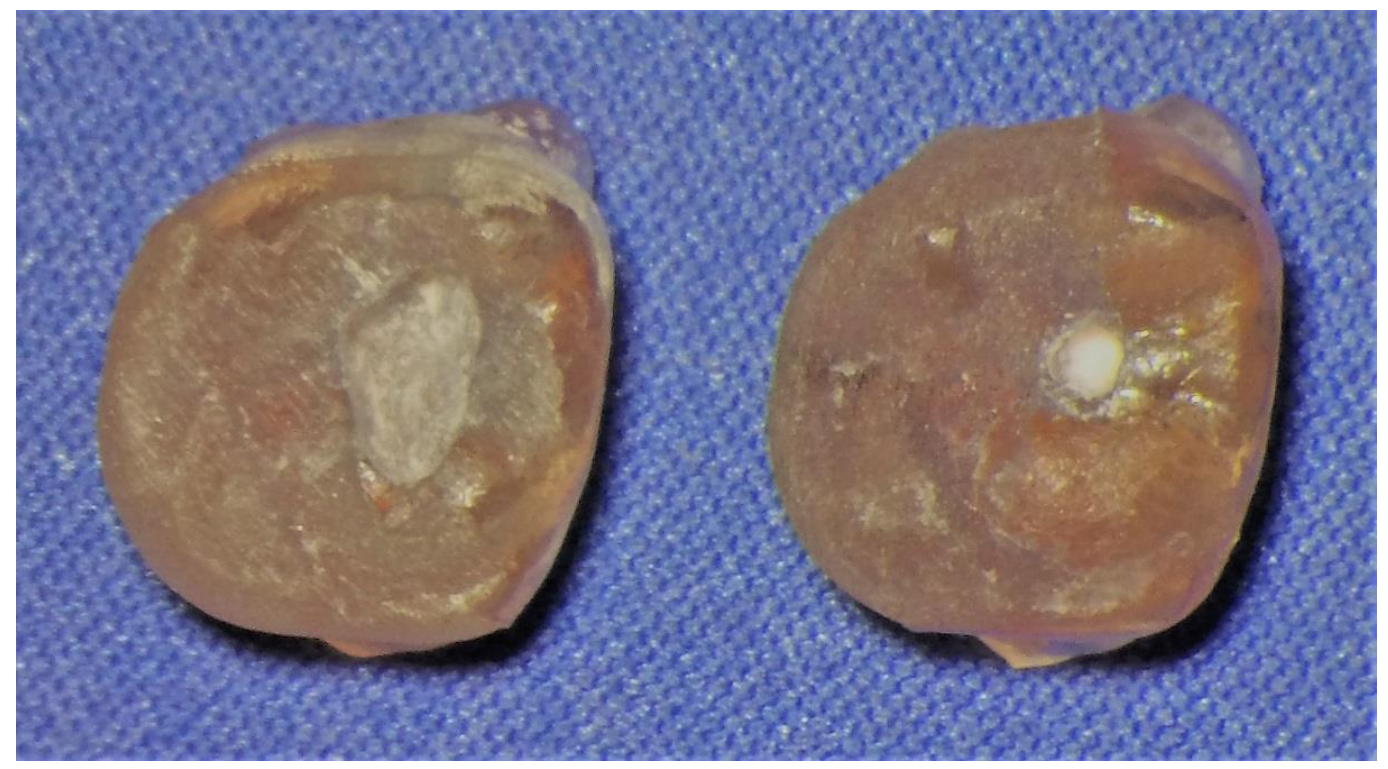

Figure 7. Occlusal view of traditional endodontic cavity on the left and contracted endodontic cavity on the right. 


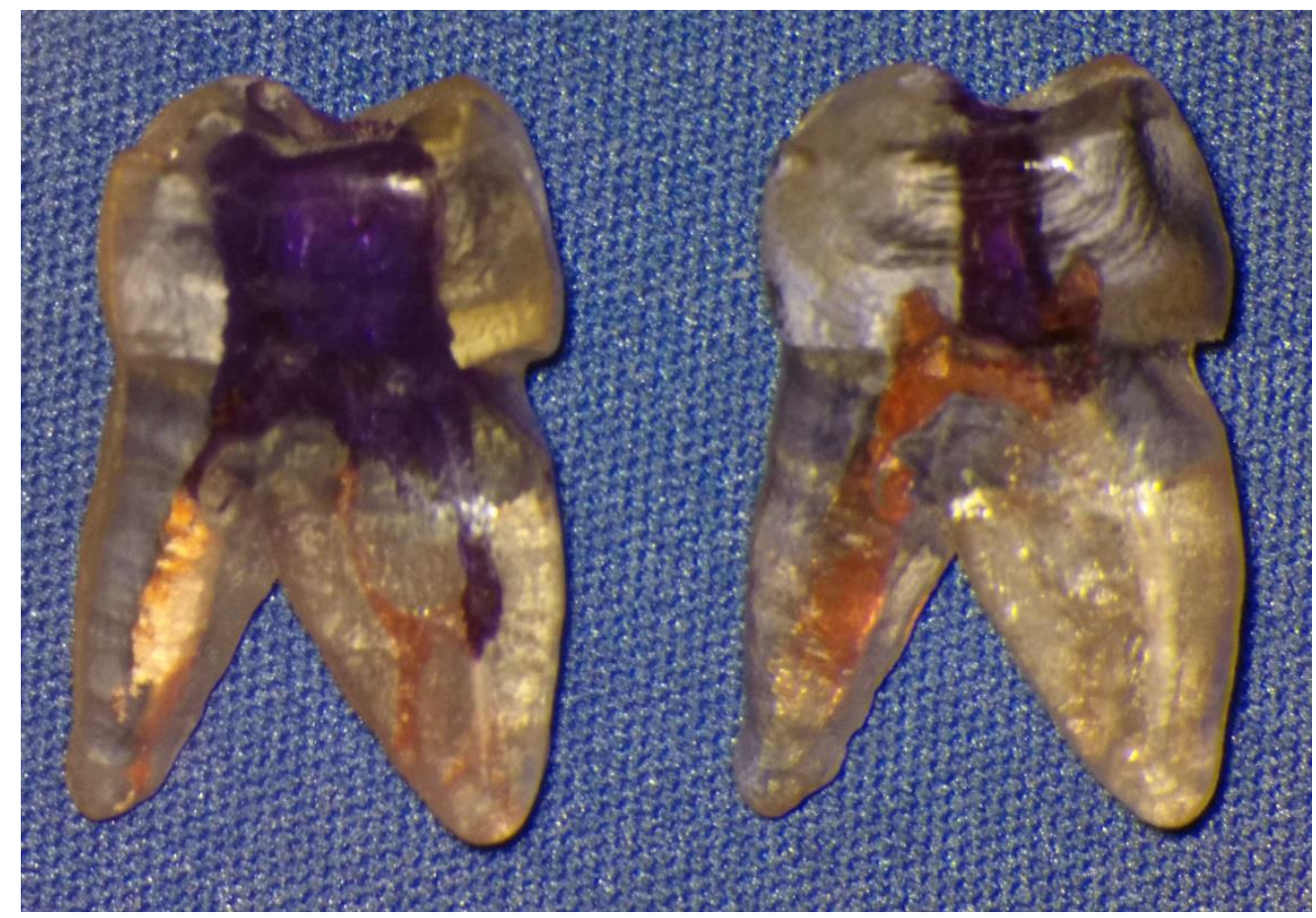

Figure 8. Coronal view from the mesial of traditional access on the left and contracted access on the right stained with methylene blue to show contrast in size.

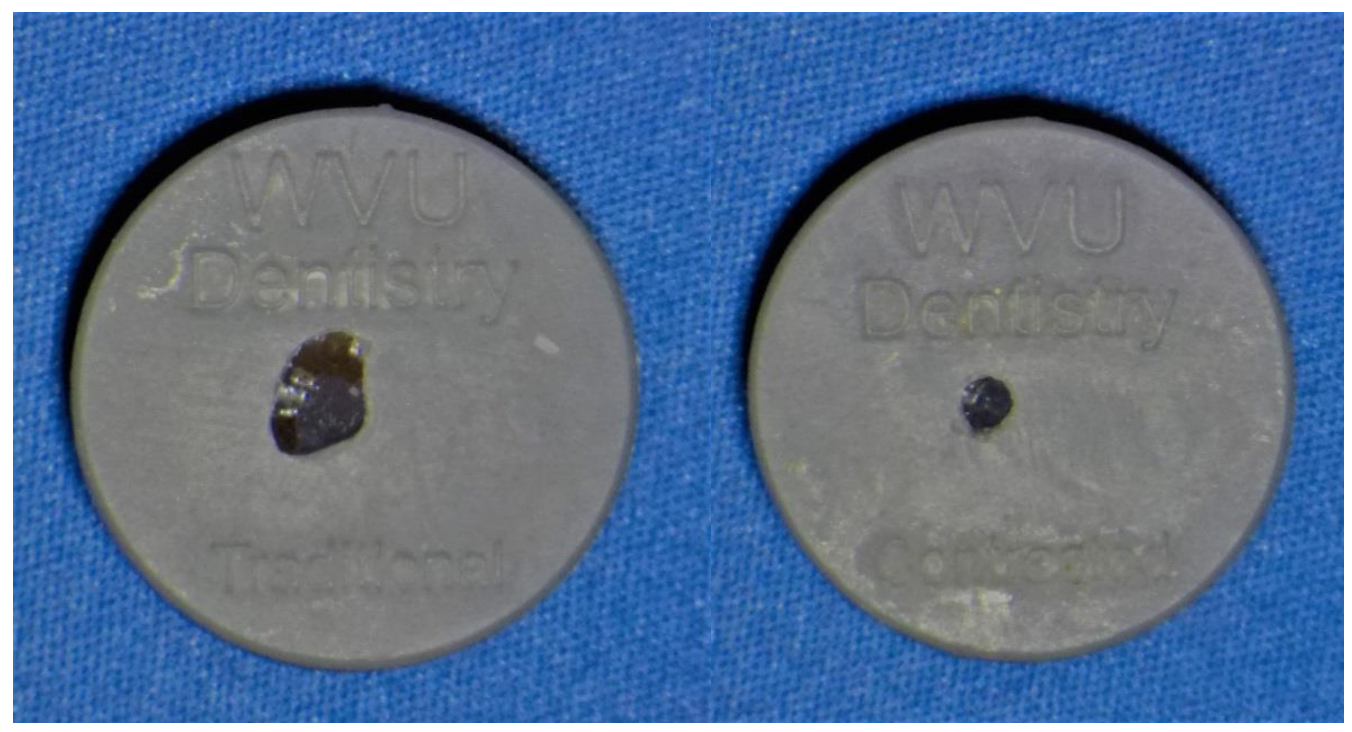

Figure 9. 3D printed stint of traditional access on the left and contracted access on the right prior to access preparation.

The working length was established $1 \mathrm{~mm}$ short of the apex and glide path was secured with size 15 K file, (Flexofile ${ }^{\circledR}$, Dentsply, York, PA, USA) (figure 10). The canals were sub-sequentially 
instrumented to length with nickel titanium rotary files according to the group they were assigned. Each mesial buccal canal instrumented in the ProTaper Next group was instrumented up to X2 (25.06). Each mesial buccal canal instrumented in the WaveOne Gold group was instrumented solely with Primary file (25.07). Speed and torque for PTN and reciprocating path for WOG were set according to the manufacturer's instructions for the specific file and were then set on the rotary motor ( $\mathrm{e}^{3}$ Tulsa Dentsply Torque Control Motor). The nickel titanium rotary files were used in accordance with the manufacturer's recommendations utilizing an in and out brushing motion. Canals were rinsed with $2 \mathrm{ml}$ of sterile water between each file change using a 30 gauge, $22 \mathrm{~mm}$ length side vented needle (Prorinse®, Dentsply, York, PA, USA). Needles were inserted as deeply as possible without binding in the canal. After irrigation, recapitualtion was completed by using a size $10 \mathrm{~K}$ file $1 \mathrm{~mm}$ beyond working length and the canal rinsed with another $2 \mathrm{ml}$ of sterile water. Once the canal was instrumented to length, a final rinse with $2 \mathrm{ml}$ of sterile water was completed in the same manner as before and the canal was dried with sterile, size 25 paper points.

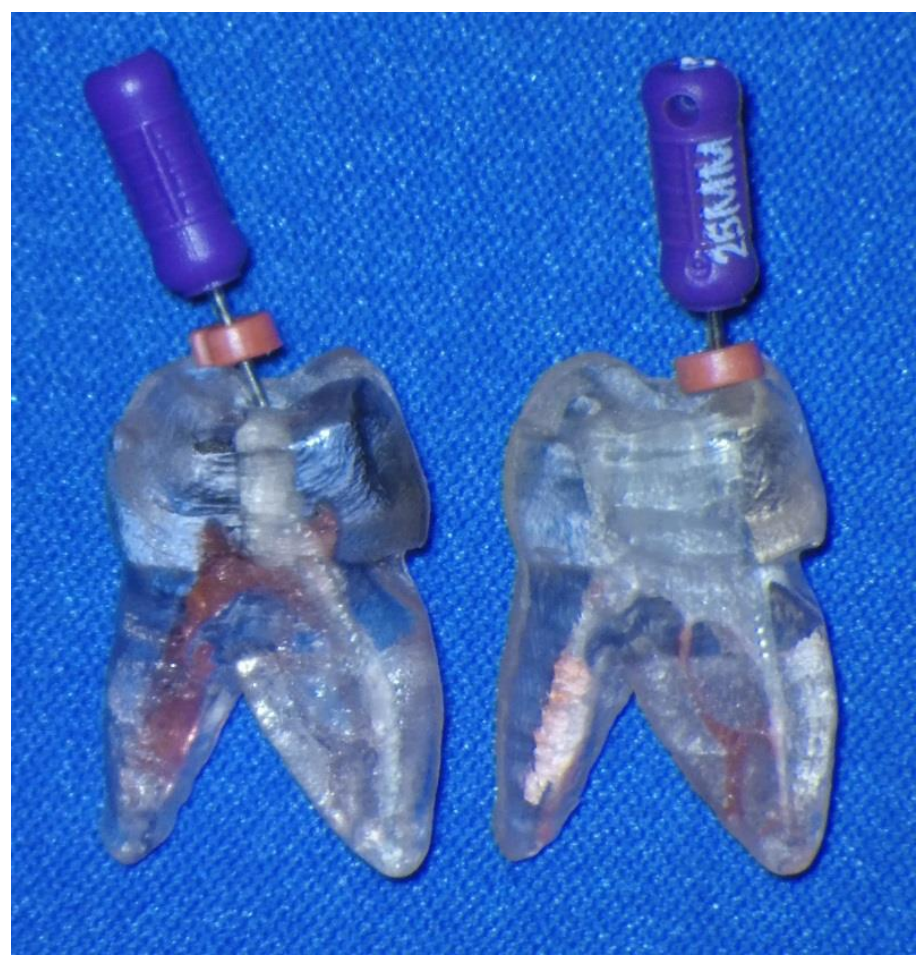

Figure 10. Proximal view from the mesial showing size 10 hand file at length and the differing path of insertion for the contracted access on the left and traditional access on the right. 
All teeth were scanned a second time after access and canal instrumentation in an identical manner to the original unaltered tooth. The images generated were also uploaded to Data Viewer, CTAn, and CTVol to evaluate the post-instrumentation root thickness of the mesial buccal at 1.0, 3.0, $5.0 \mathrm{~mm}$ 's from the apex. 


\section{Chapter 4}

\section{Results}

1. DESCRIPTIVE STATISTICS

\begin{tabular}{|c|c|c|c|c|c|c|}
\hline $\begin{array}{l}\text { Distance } \\
\text { From Apex } \\
(\mathrm{mm})\end{array}$ & File & $\begin{array}{l}\text { Access } \\
\text { Design }\end{array}$ & $\begin{array}{c}\text { Mean Canal } \\
\text { Transportation }\end{array}$ & $\begin{array}{c}\text { Standard } \\
\text { Deviation }\end{array}$ & $\begin{array}{c}\text { Mean } \\
\text { Centering } \\
\text { ratio }\end{array}$ & $\begin{array}{c}\text { Standard } \\
\text { Deviation }\end{array}$ \\
\hline \multirow[t]{4}{*}{1} & WOG & Traditional & 0.196617 & 0.132380 & 0.229744 & 0.179514 \\
\hline & & Contracted & 0.417426 & 0.283868 & 0.243252 & 0.223348 \\
\hline & PTN & Traditional & 0.156008 & 0.133665 & 0.251536 & 0.196147 \\
\hline & & Contracted & 0.352733 & 0.350523 & 0.278816 & 0.210200 \\
\hline \multirow[t]{4}{*}{3} & WOG & Traditional & 0.045415 & 0.036511 & 0.689652 & 0.224106 \\
\hline & & Contracted & 0.085429 & 0.065323 & 0.522503 & 0.309780 \\
\hline & PTN & Traditional & 0.029700 & 0.028939 & 0.706717 & 0.225826 \\
\hline & & Contracted & 0.030658 & 0.022124 & 0.505885 & 0.254495 \\
\hline \multirow[t]{4}{*}{5} & WOG & Traditional & 0.083863 & 0.049439 & 0.474823 & 0.265267 \\
\hline & & Contracted & 0.158708 & 0.064156 & 0.258515 & 0.269138 \\
\hline & PTN & Traditional & 0.053569 & 0.047481 & 0.600052 & 0.233049 \\
\hline & & Contracted & 0.069661 & 0.041159 & 0.408275 & 0.286203 \\
\hline
\end{tabular}

Table 1. Means and Standard Deviations (of Absolute Value Variable)

\section{ANALYSIS OF VARIANCE WITH INTERACTION TERM}

Canal transport at distance $3 \mathrm{~mm}$ and $5 \mathrm{~mm}$ have significant interaction $\mathrm{p}$-values (Table 2), thus necessitating a Tukey test to see where the difference lies. 


\begin{tabular}{|c|c|c|c|}
\hline \multicolumn{2}{|c|}{ Two-way ANOVA } & $\begin{array}{l}\text { Canal } \\
\text { Transport }\end{array}$ & Centering Ratio \\
\hline $\begin{array}{l}\text { Distance From } \\
\text { Apex }(\mathrm{mm})\end{array}$ & Variable & P-value & P-value \\
\hline \multirow{3}{*}{1} & File & 0.284 & 0.4816 \\
\hline & Access & $4.56 \mathrm{E}-05$ & 0.6165 \\
\hline & File:Access & 0.8059 & 0.8656 \\
\hline \multirow{3}{*}{3} & Drill & $5.252 \mathrm{e}-05$ & 0.9965 \\
\hline & Access & 0.01563 & 0.0005146 \\
\hline & File:Access & $0.02101 *$ & 0.74283 \\
\hline \multirow{3}{*}{5} & Drill & 7.72E-08 & 0.0107087 \\
\hline & Access & $2.45 \mathrm{E}-05$ & 0.0002036 \\
\hline & File:Access & $0.005111^{*}$ & 0.8168805 \\
\hline
\end{tabular}

Table 2. Two-way ANOVA of file and access interaction

\section{INTERACTION PLOTS}

To confirm the presence or absence of any interaction effects as indicated in the above two-way ANOVA, interaction plots (Figure 11) were created for canal transport and centering ratio for each depth. Lines that are more parallel indicate less of an interaction between file type and access type while less parallel lines or intersecting lines indicate a stronger interaction between drill type and access type.
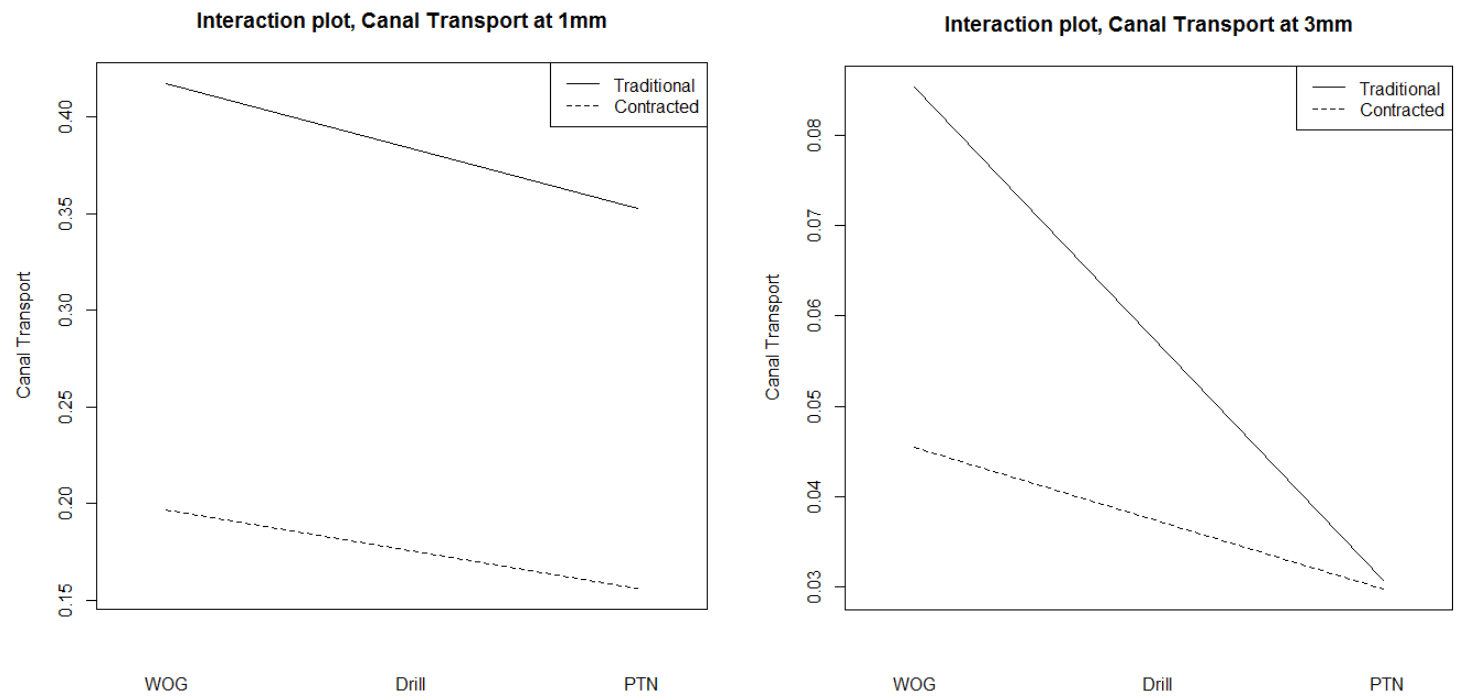

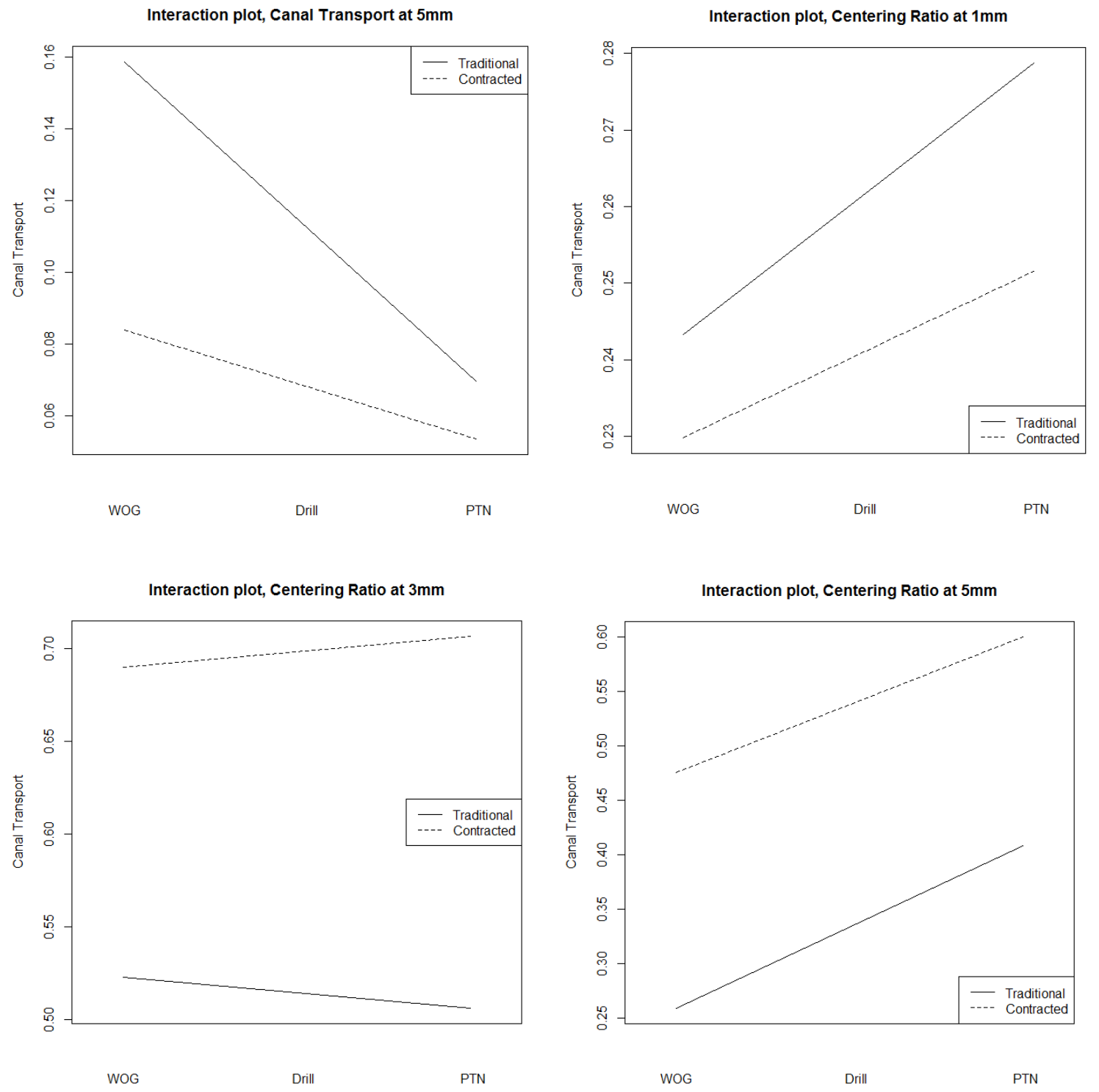

Figure 11. Various interaction plots for potential variable interactions

These interaction plots confirm the conclusions drawn from the two-way ANOVA regarding the interaction between file type and access design in that the interaction only appears significant for canal transport at the depths of $3 \mathrm{~mm}$ and $5 \mathrm{~mm}$. 


\section{ANALYSIS WITHOUT INTERACTION TERM}

The following two-way ANOVA (Table 3) evaluates whether the means differ between file groups and access groups without the interaction term, since the interaction term was found not to be significant.

\begin{tabular}{|c|l|r|r|}
\hline \multicolumn{2}{|l|}{ Simpler Two-way ANOVA } & \multicolumn{2}{l|}{$\begin{array}{l}\text { Centering } \\
\text { Ratio }\end{array}$} \\
\hline Distance (mm) & Variable & P-value & \multicolumn{1}{l|}{ P-value } \\
\hline 1 & File & 0.2817 & 0.4794 \\
\hline & Access & $4.19 \mathrm{E}-05^{*}$ & 0.6147 \\
\hline 3 & File & - & 0.9965 \\
\hline & Access & - & $0.0004843^{*}$ \\
\hline 5 & File & - & $0.0103267^{*}$ \\
\hline & Access & - & $0.0001892^{*}$ \\
\hline
\end{tabular}

Table 3. Two-way ANOVA without interaction

There are significant differences in both file and access design at $5 \mathrm{~mm}$ for centering ratio. There is also a significant difference for access at $3 \mathrm{~mm}$ for centering ratio and at $1 \mathrm{~mm}$ for canal transport.

The differences in means were calculated along with the upper and lower bounds of those differences using Tukey's Honest Significant Difference method (Table 4) for the groups that have different means as indicated in the above two-way ANOVA. The upper and lower bounds were calculated using $95 \%$ family-wise confidence levels. The individual confidence levels of the comparisons are adjusted so that the overall confidence level is $95 \%$. The p-values are excluded since they are the same as in the above two-way ANOVA results.

\begin{tabular}{|c|l|c|r|c|}
\hline \multicolumn{4}{|c|}{ Canal Transport } \\
\hline Depth & Comparison & Difference & Lower Bound & $\begin{array}{l}\text { Upper } \\
\text { Bound }\end{array}$ \\
\hline $1 \mathrm{~mm}$ & Contracted - Traditional & 0.208767 & 0.112242 & 0.305292 \\
\hline
\end{tabular}

Centering Ratio 


\begin{tabular}{|c|l|r|l|r|} 
Depth & Comparison & Difference & $\begin{array}{l}\text { Lower } \\
\text { Bound }\end{array}$ & \multicolumn{1}{|l|}{ Upper Bound } \\
\hline \multirow{2}{*}{$3 \mathrm{~mm}$} & $\begin{array}{l}\text { Contracted }- \\
\text { Traditional }\end{array}$ & -0.183990 & -0.285103 & -0.082878 \\
\hline \multirow{2}{*}{$5 \mathrm{~mm}$} & PTN - WOG & 0.137494 & 0.033168 & 0.241821 \\
\cline { 2 - 5 } & $\begin{array}{l}\text { Contracted - } \\
\text { Traditional }\end{array}$ & -0.204042 & -0.308369 & \\
\hline
\end{tabular}

Table 4. Upper and Lower bounds for significant interaction variables

For canal transport at $1 \mathrm{~mm}$ contracted access design has higher canal transport than the traditional access type regardless of the file tested. At depths of $3 \mathrm{~mm}$ and $5 \mathrm{~mm}$, the traditional access type has a higher centering ratio than the contracted access type regardless of drill type. At a depth of $5 \mathrm{~mm}$, the PTN file has a higher centering ratio than the WOG file regardless of access type.

\section{ANALYSIS WITH INTERACTION TERM}

The following is a multiple comparison analysis of canal transport at distances $3 \mathrm{~mm}$ and $5 \mathrm{~mm}$. The four groups, as shown in the key, were compared with a one-way ANOVA. Again, 95\% family-wise confidence levels were used for the upper and lower bounds for the comparisons.

\begin{tabular}{|l|l|}
\hline Group Key & \\
\hline A & WOG, Traditional \\
\hline B & WOG, Contracted \\
\hline C & PTN, Traditional \\
\hline D & PTN, Contracted \\
\hline
\end{tabular}




\begin{tabular}{|l|r|r|r|r|}
\hline \multicolumn{5}{|c|}{ Canal Transport at Distance $\mathbf{3 ~ m m}$} \\
\hline $\begin{array}{l}\text { Group } \\
\text { Comparison** }\end{array}$ & \multicolumn{1}{|l|}{ Difference } & $\begin{array}{l}\text { Lower } \\
\text { Bound }\end{array}$ & Upper Bound & \multicolumn{1}{l|}{ p-value } \\
\hline B-A & 0.040015 & 0.009240 & 0.070790 & $0.0054^{*}$ \\
\hline C-A & -0.015714 & -0.046489 & 0.015061 & 0.5430 \\
\hline D-A & -0.014757 & -0.045532 & 0.016018 & 0.5944 \\
\hline C-B & -0.055729 & -0.086504 & -0.024954 & $<0.0001^{*}$ \\
\hline D-B & -0.054772 & -0.085547 & -0.023997 & $<0.0001^{*}$ \\
\hline D-C & 0.000957 & -0.029818 & 0.031732 & 0.9998 \\
\hline
\end{tabular}

\begin{tabular}{|l|r|r|r|r|}
\hline \multicolumn{5}{|c|}{ Canal Transport at Distance = 5 mm } \\
\hline $\begin{array}{l}\text { Group } \\
\text { Comparison** }\end{array}$ & \multicolumn{1}{|l|}{ Difference } & $\begin{array}{l}\text { Lower } \\
\text { Bound }\end{array}$ & Upper Bound & \multicolumn{1}{l|}{ p-value } \\
\hline B-A & 0.074845 & 0.036942 & 0.112748 & $<0.0001^{*}$ \\
\hline C-A & -0.030294 & -0.068197 & 0.007608 & 0.1638 \\
\hline D-A & -0.014202 & -0.052105 & 0.023701 & 0.7613 \\
\hline C-B & -0.105140 & -0.143042 & -0.067237 & $<0.0001 *$ \\
\hline D-B & -0.089047 & -0.126950 & -0.051145 & $<0.0001^{*}$ \\
\hline D-C & 0.016092 & -0.021811 & 0.053995 & 0.6842 \\
\hline
\end{tabular}

Table 5. Tukey HSD Comparisons

When file type is held constant at WOG, the average difference in canal transport when access type is contracted is different to when access type is traditional. So, contracted access design produces a higher average of canal transport than traditional when WOG was used. When file type is held constant at PTN, the average canal transport is not different between contracted and traditional access type. When access type is held constant at traditional, the average canal transport is not different between PTN and WOG. When access type is held constant at contracted WOG has a higher average of canal transport than PTN. There is no difference in averages of canal transport when access type is contracted and PTN is used compared to when access type is traditional and WOG

These conclusions hold at both $3 \mathrm{~mm}$ and $5 \mathrm{~mm}$. At $5 \mathrm{~mm}$, the differences in averages are larger than at $3 \mathrm{~mm}$.

\section{INCIDENTIAL FINDINGS}

During length determination and establishment of apical patency, there were three teeth where the apex was never patent. All three of these teeth were in the contracted endodontic cavity group and were discarded from the study. One file broke during instrumentation. 
Approximately $2 \mathrm{~mm}$ of a stainless steel size 10 hand file separated in the apical third during an attempt to establish apical patency. This tooth was also in the contracted endodontic cavity group and discarded from further study. There was also a higher tendency in the contacted endodontic cavity group to create ledges when using hand files. All the ledges were able to be bypassed.

\section{$\underline{\text { Discussion }}$}

The study was designed to determine the canal transportation and centering ability of two different endodontic rotary files when used in conjunction with two different access cavity designs. Canal transportation at $1 \mathrm{~mm}, 3 \mathrm{~mm}$, and $5 \mathrm{~mm}$ was found to be higher overall using a contracted access regardless of the file used. However, the difference was most significant at $3 \mathrm{~mm}$ and 5 $\mathrm{mm}$. Centering ratio was also found to be significant for access design at $1 \mathrm{~mm}$ and $3 \mathrm{~mm}$. As a whole, the traditional endodontic cavity produced a more centered canal preparation than that of the contracted endodontic cavity.

Teeth accessed and instrumented with a combination of WaveOne Gold® and contracted endodontic access produced the highest overall transportation. ProTaper NEXT® however did not show a significant difference in canal transportation when used with either contracted or traditional endodontic access. There was also no significant difference in canal transportation at any level between WOG and PTN when access type was held constant at traditional, although WOG did have a slightly higher amount of canal transportation. Interestingly, there was no significant difference in canal transportation when a combination of ProTaper NEXT® and contracted endodontic cavity was compared to WaveOne Gold ${ }^{\circledR}$ and traditional endodontic access.

This variation in canal transportation could be due to several factors. It would seem that one of the limitations of the WOG system is the relatively large tip size of 25.07 that serves as the first file taken to length when compared to the 17.04 size of the ProTaper NEXT X1 that is first taken to length. While the manufacturer of both files systems recommends using a pecking inward and then a brushing outward stroke the WaveOne Gold primary file required several more rounds of pecking and a stronger brush stroke out to reach length than either of the ProTaper NEXT files used. This relationship was even more apparent when using the contracted access. It can also be postulated that the smaller file and off access rotation of the ProTaper NEXT reduced the canal 
wall contact time from that of the Wave One Gold leading to a less aggressive instrumentation and less time for transportation to happen.
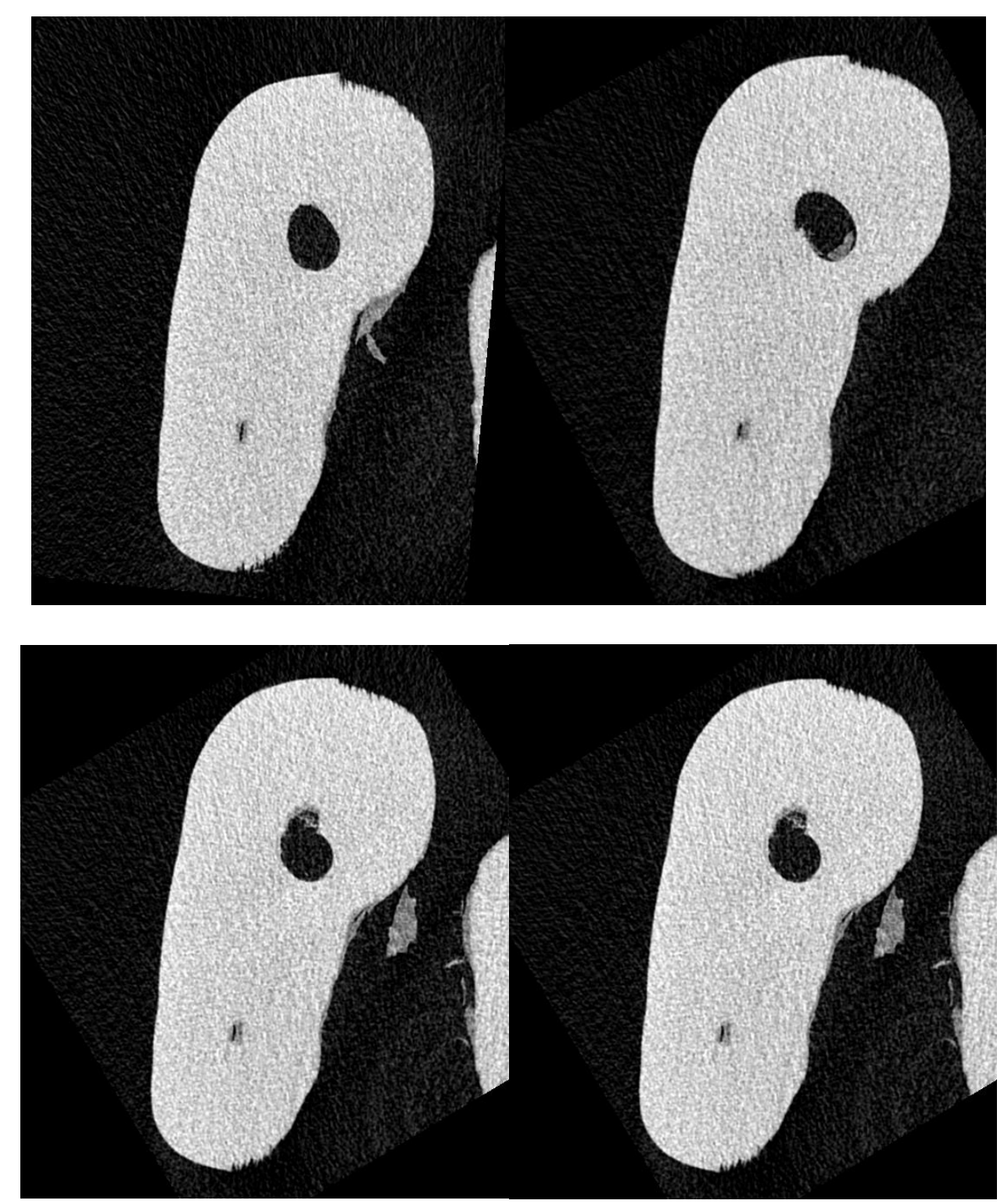

Figure 12. Micro CT images of various access and file combination at $5 \mathrm{~mm}$ where the interaction was found to be most significant. Upper right PTN/TEC. Upper Right WOG/TEC. Lower Right PTN/CEC. Lower left WOG/CEC 
Mesial buccal roots of maxillary first molars were chosen for this study for the frequency with which they are treated as well as their typically accentuated curve and broadness of root mesial-distally. These factors add to the challenge of chemo-mechanical debridement of the tooth and make cleaning and shaping of these canals difficult, particularly in the isthmus and apical area which are prone to iatrogenic errors.

The goals of cleaning and shaping of the entire root canal system to obtain optimum pain reduction and periapical healing have been discussed. These principles ideally result in a canal that is a continuously tapering funnel from apex to orifice, follows the original canal shape and maintains the original apex in relation to the periapical tissue as well as the external root surface (2). It is harder to achieve these goals in curved roots, such as those common in maxillary first molars. For that reason there is an increased chance of procedural errors such as canal transportation, zipping of the apex, strip perforation and ledging (64).

Variations in canal anatomy such as comparing straight vs. curved, round vs. oval, or narrow vs. wide root morphology can play a substantial role in determining the final postinstrumentation shape of the canal (13). Canals of the mesial buccal root of maxillary first molars which tend to be more ribbon shaped or flat, would have greater unprepared canal area, greater canal transportation as well as other procedural errors when compared to that of the larger and straighter palatal root of the same maxillary first molar. Differing ideas and techniques have been proposed over the years to address the challenges in cleaning and shaping that are presented by curved canals. It is generally accepted that nickel titanium rotary files of all patterns of rotation reduce procedural errors when compared to traditional stainless steel hand files (65). This study's finding of an increase in canal transportation must be taken into consideration along with others comparing ProTaper NEXT and other reciprocating files ability to remove obturation material from curved roots (66). Similarly, one study on the effect of contracted access in retreatment scenarios found them to limit the efficiency of gutta percha removal (37). Taking all these factors into consideration, it may not be advisable to use contracted endodontic cavities or a reciprocating file in retreatment situations.

There is currently a trend in endodontics and dentistry as a whole towards a minimalistic approach to treatment which drives clinicians preforming endodontics to smaller accesses with 
less focus on straight line access and coronal flaring than previously advocated. This has become a large area of research as has been reviewed earlier in this work.

Similar to historical articles studying access and instrumentation, the current articles assessing contracted access, the outcome factors of interest are canal detection, instrumentation efficiency, and fracture resistance (16). A related study using micro CT and histological sections evaluating dentin conservation and debridement using mesial roots of maxillary molars found that radicular debridement was not statistically different between conservative and traditional access design (67). These findings have been corroborated in other similar debridement studies $(15,36)$. One interesting finding of the Neelakantan study was the significant compromise in the ability to debride the coronal pulp space when using a contracted access (67). This under debrided area represents a possible reason for treatment failure.

Another micro CT study published in 2016 also evaluated apical canal transportation of WaveOne Gold $®$ at $1 \mathrm{~mm}$ and $3 \mathrm{~mm}$ from the apex found a higher incidence of canal transportation when utilizing a contracted access when compared to a traditional access (68). While this study evaluated extracted mandibular molars the results are similar enough to that of the present study to establish a parallel between the two.

There are those in the endodontic community who insist that contracted accesses provide superior fracture resistance without significant compromise to the instrumentation process. However, a recent Brazilian study, also utilizing maxillary teeth and a reciprocating file found greater canal transportation and lower success in locating canals when using a contracted access while providing no difference regarding fracture resistance when compared to a traditional access (16).

\section{Chapter 5}

\section{Conclusions}

The benefit of contracted endodontic access cavities remains controversial while the utilization of these accesses appears to be growing. To this point there has been no study to do a direct comparison of differing file designs and their utilization in relationship to the size of 
coronal access in maxillary molar teeth. This study is in agreement with others that contacted endodontic cavities produced more canal transportation overall. It also confirms that the ProTaper NEXT® continuous motion file performed better than the WaveOne Gold® reciprocating file in the presence of a contracted access. Within the boundaries of this study it appears that there is no significant benefit to a contracted endodontic cavity over a traditional access. 


\section{$\underline{\text { References }}$}

1. Christie WH; Thompson GK. The importance of endodontic access in locating maxillary and mandibular molar canals. Journal (Canadian Dental Association). 1994;60(6):527-32, 35-6. 2. Schilder H. Cleaning and shaping the root canal. Dent Clin North Am. 1974;18(2):26996.

3. Gergi R; Rjeily JA; Sader J; Naaman A. Comparison of canal transportation and centering ability of twisted files, Pathfile-ProTaper system, and stainless steel hand K-files by using computed tomography. J Endod. 2010;36(5):904-7.

4. Weine FS; Kelly RF; Lio PJ. The effect of preparation procedures on original canal shape and on apical foramen shape. Journal of Endodontics;1(8):255-62.

5. Peters OA; Laib A; Göhring TN; Barbakow F. Changes in Root Canal Geometry after Preparation Assessed by High-Resolution Computed Tomography. Journal of Endodontics;27(1):1-6.

6. Verma P; Love RM. A Micro CT study of the mesiobuccal root canal morphology of the maxillary first molar tooth. Int Endod J. 2011;44(3):210-7.

7. Zhao D; Shen Y; Peng B; Haapasalo M. Micro-computed tomography evaluation of the preparation of mesiobuccal root canals in maxillary first molars with Hyflex CM, Twisted Files, and K3 instruments. J Endod. 2013;39(3):385-8.

8. Cleghorn BM; Christie WH; Dong CCS. Root and Root Canal Morphology of the Human Permanent Maxillary First Molar: A Literature Review. Journal of Endodontics;32(9):813-21.

9. Hollanda AC; de Alencar AH; Estrela CR; Bueno MR; Estrela C. Prevalence of endodontically treated teeth in a Brazilian adult population. Braz Dent J. 2008;19(4):313-7.

10. Baratto Filho F; Zaitter S; Haragushiku GA; de Campos EA; Abuabara A; Correr GM. Analysis of the Internal Anatomy of Maxillary First Molars by Using Different Methods. Journal of Endodontics;35(3):337-42.

11. Bergmans L; Van Cleynenbreugel J; Wevers M; Lambrechts P. A methodology for quantitative evaluation of root canal instrumentation using microcomputed tomography. Int Endod J. 2001;34(5):390-8.

12. Nielsen RB; Alyassin AM; Peters DD; Carnes DL; Lancaster J. Microcomputed tomography: an advanced system for detailed endodontic research. J Endod. 1995;21(11):561-8. 13. Peters OA; Peters CI; Schonenberger K; Barbakow F. ProTaper rotary root canal preparation: effects of canal anatomy on final shape analysed by micro CT. Int Endod J. 2003;36(2):86-92.

14. Clark D; Khademi JA. Case studies in modern molar endodontic access and directed dentin conservation. Dent Clin North Am. 2010;54(2):275-89.

15. Moore B; Verdelis K; Kishen A; Dao T; Friedman S. Impacts of Contracted Endodontic Cavities on Instrumentation Efficacy and Biomechanical Responses in Maxillary Molars. Journal of Endodontics;42(12):1779-83. 
16. Rover G; Belladonna FG; Bortoluzzi EA; De-Deus G; Silva EJNL; Teixeira CS. Influence of Access Cavity Design on Root Canal Detection, Instrumentation Efficacy, and Fracture Resistance Assessed in Maxillary Molars. Journal of Endodontics;43(10):1657-62. 17. Aggarwal V; Singla M; Logani A; Shah N. Endodontic Management of a Maxillary First Molar with Two Palatal Canals with the Aid of Spiral Computed Tomography: A Case Report. Journal of Endodontics;35(1):137-9.

18. Paqué F; Ganahl D; Peters OA. Effects of Root Canal Preparation on Apical Geometry Assessed by Micro Computed Tomography. Journal of Endodontics;35(7):1056-9.

19. Ferguson DB; Kjar KS; Hartwell GR. Three Canals in the Mesiobuccal Root of a Maxillary First Molar: A Case Report. Journal of Endodontics;31(5):400-2.

20. Jung I-Y; Seo M-A; Fouad AF; Spångberg LSW; Lee S-J; Kim H-J, et al. Apical Anatomy in Mesial and Mesiobuccal Roots of Permanent First Molars. Journal of Endodontics;31(5):364-8.

21. Degerness R; Bowles W. Anatomic Determination of the Mesiobuccal Root Resection Level in Maxillary Molars. Journal of Endodontics;34(10):1182-6.

22. Markvart M; Darvann TA; Larsen P; Dalstra M; Kreiborg S; Bjorndal L. Micro-CT analyses of apical enlargement and molar root canal complexity. Int Endod J. 2012;45(3):273-81. 23. Briseno-Marroquin B; Paque F; Maier K; Willershausen B; Wolf TG. Root Canal Morphology and Configuration of 179 Maxillary First Molars by Means of Micro-computed Tomography: An Ex Vivo Study. J Endod. 2015;41(12):2008-13.

24. Marroquín BB; El-Sayed MAA; Willershausen-Zönnchen B. Morphology of the Physiological Foramen: I. Maxillary and Mandibular Molars. Journal of Endodontics;30(5):3218.

25. Lee J-K; Ha B-H; Choi J-H; Heo S-M; Perinpanayagam H. Quantitative ThreeDimensional Analysis of Root Canal Curvature in Maxillary First Molars Using MicroComputed Tomography. Journal of Endodontics;32(10):941-5.

26. Deutsch AS; Musikant BL. Morphological Measurements of Anatomic Landmarks in Human Maxillary and Mandibular Molar Pulp Chambers. Journal of Endodontics;30(6):388-90. 27. Goerig AC; Michelich RJ; Schultz HH. Instrumentation of root canals in molar using the step-down technique. Journal of Endodontics;8(12):550-4.

28. Schroeder KP; Walton RE; Rivera EM. Straight Line Access and Coronal Flaring: Effect on Canal Length. Journal of Endodontics;28(6):474-6.

29. Krasner P; Rankow HJ. Anatomy of the Pulp-Chamber Floor. Journal of Endodontics;30(1):5-16.

30. Murray P. Endodontic Access Considerations Based on Root Canal Morphology. A Concise Guide to Endodontic Procedures. Berlin, Heidelberg: Springer Berlin Heidelberg; 2015. p. 117-30.

31. Darda S; Manwar N; Chandak M; Shori DD. An in vivo evaluation of two types of files used to accurately determine the diameter of the apical constriction of a root canal: an in vivo study. J Contemp Dent Pract. 2009;10(4):43-50.

32. Borges ÁH; Pereira TM; Porto AN; de Araújo Estrela CR; Miranda Pedro FL; Aranha AMF, et al. The Influence of Cervical Preflaring on the Amount of Apically Extruded Debris after Root Canal Preparation Using Different Instrumentation Systems. Journal of Endodontics;42(3):465-9. 
33. Eaton JA; Clement DJ; Lloyd A; Marchesan MA. Micro-Computed Tomographic Evaluation of the Influence of Root Canal System Landmarks on Access Outline Forms and Canal Curvatures in Mandibular Molars. Journal of Endodontics;41(11):1888-91.

34. Clark D; Khademi J. Modern molar endodontic access and directed dentin conservation. Dent Clin North Am. 2010;54(2):249-73.

35. Ericson D. What is minimally invasive dentistry? Oral Health Prev Dent. 2004;2 Suppl 1:287-92.

36. Krishan R; Paque F; Ossareh A; Kishen A; Dao T; Friedman S. Impacts of conservative endodontic cavity on root canal instrumentation efficacy and resistance to fracture assessed in incisors, premolars, and molars. J Endod. 2014;40(8):1160-6.

37. Niemi TK; Marchesan MA; Lloyd A; Seltzer RJ. Effect of Instrument Design and Access Outlines on the Removal of Root Canal Obturation Materials in Oval-shaped Canals. Journal of Endodontics;42(10):1550-4.

38. Siqueira JF, Jr.; Lima KC; Magalhães FAC; Lopes HP; de Uzeda M. Mechanical reduction of the bacterial population in the root canal by three instrumentation techniques. Journal of Endodontics;25(5):332-5.

39. Dillon JS; Amita; Gill B. To determine whether the first file to bind at the working length corresponds to the apical diameter in roots with apical curvatures both before and after preflaring. J Conserv Dent. 2012;15(4):363-6.

40. Wu M-K; Fan B; Wesselink PR. Leakage Along Apical Root Fillings in Curved Root Canals. Part I: Effects of Apical Transportation on Seal of Root Fillings. Journal of Endodontics;26(4):210-6.

41. Rodrigues RCV; Zandi H; Kristoffersen AK; Enersen M; Mdala I; Ørstavik D, et al. Influence of the Apical Preparation Size and the Irrigant Type on Bacterial Reduction in Root Canal-treated Teeth with Apical Periodontitis. Journal of Endodontics. 2017;43(7):1058-63.

42. Kherlakian D; Cunha RS; Ehrhardt IC; Zuolo ML; Kishen A; da Silveira Bueno CE. Comparison of the Incidence of Postoperative Pain after Using 2 Reciprocating Systems and a Continuous Rotary System: A Prospective Randomized Clinical Trial. Journal of Endodontics;42(2):171-6.

43. Dalton BC; Orstavik D; Phillips C; Pettiette M; Trope M. Bacterial reduction with nickeltitanium rotary instrumentation. J Endod. 1998;24(11):763-7.

44. Card SJ; Sigurdsson A; Orstavik D; Trope M. The effectiveness of increased apical enlargement in reducing intracanal bacteria. J Endod. 2002;28(11):779-83.

45. Arias A; Singh R; Peters OA. Torque and Force Induced by ProTaper Universal and ProTaper Next during Shaping of Large and Small Root Canals in Extracted Teeth. Journal of Endodontics;40(7):973-6.

46. Ye J; Gao Y. Metallurgical characterization of M-Wire nickel-titanium shape memory alloy used for endodontic rotary instruments during low-cycle fatigue. J Endod. 2012;38(1):1057.

47. Topçuoğlu HS; Topçuoğlu G; Akti A; Düzgün S. Comparison of Cyclic Fatigue Resistance of ProTaper Next, HyFlex CM, OneShape, and ProTaper Universal Instruments in a Canal with a Double Curvature. Journal of Endodontics;42(6):969-71.

48. Zanesco C; Só MVR; Schmidt S; Fontanella VRC; Grazziotin-Soares R; Barletta FB. Apical Transportation, Centering Ratio, and Volume Increase after Manual, Rotary, and Reciprocating Instrumentation in Curved Root Canals: Analysis by Micro-computed Tomographic and Digital Subtraction Radiography. Journal of Endodontics;43(3):486-90. 
49. Capar ID; Ertas H; Ok E; Arslan H; Ertas ET. Comparative study of different novel nickel-titanium rotary systems for root canal preparation in severely curved root canals. J Endod. 2014;40(6):852-6.

50. Marceliano-Alves MF; Sousa-Neto MD; Fidel SR; Steier L; Robinson JP; Pecora JD, et al. Shaping ability of single-file reciprocating and heat-treated multifile rotary systems: a microCT study. Int Endod J. 2015;48(12):1129-36.

51. Özyürek T. Cyclic Fatigue Resistance of Reciproc, WaveOne, and WaveOne Gold Nickel-Titanium Instruments. Journal of Endodontics;42(10):1536-9.

52. Venino PM; Citterio CL; Pellegatta A; Ciccarelli M; Maddalone M. A Microcomputed Tomography Evaluation of the Shaping Ability of Two Nickel-titanium Instruments, HyFlex EDM and ProTaper Next. Journal of Endodontics;43(4):628-32.

53. Gagliardi J; Versiani MA; de Sousa-Neto MD; Plazas-Garzon A; Basrani B. Evaluation of the Shaping Characteristics of ProTaper Gold, ProTaper NEXT, and ProTaper Universal in Curved Canals. Journal of Endodontics;41(10):1718-24.

54. Pérez-Higueras JJ; Arias A; de la Macorra JC; Peters OA. Differences in Cyclic Fatigue Resistance between ProTaper Next and ProTaper Universal Instruments at Different Levels. Journal of Endodontics;40(9):1477-81.

55. Karataş E; Gündüz HA; Kırıcı DÖ; Arslan H; Topçu MÇ; Yeter KY. Dentinal Crack Formation during Root Canal Preparations by the Twisted File Adaptive, ProTaper Next, ProTaper Universal, and WaveOne Instruments. Journal of Endodontics;41(2):261-4.

56. Kirchhoff AL; Fariniuk LF; Mello I. Apical Extrusion of Debris in Flat-oval Root Canals after Using Different Instrumentation Systems. Journal of Endodontics;41(2):237-41.

57. Aminoshariae A; Kulild J. Master apical file size - smaller or larger: a systematic review of microbial reduction. Int Endod J. 2015;48(11):1007-22.

58. Mickel AK; Chogle S; Liddle J; Huffaker K; Jones JJ. The role of apical size determination and enlargement in the reduction of intracanal bacteria. J Endod. 2007;33(1):21-3. 59. Brunson M; Heilborn C; Johnson DJ; Cohenca N. Effect of apical preparation size and preparation taper on irrigant volume delivered by using negative pressure irrigation system. $\mathrm{J}$ Endod. 2010;36(4):721-4.

60. Rodrigues RCV; Zandi H; Kristoffersen AK; Enersen M; Mdala I; Ørstavik D, et al. Influence of the Apical Preparation Size and the Irritant Type on Bacterial Reduction in Root Canal-treated Teeth with Apical Periodontitis. Journal of Endodontics;43(7):1058-63.

61. Souza RA; Dantas JC; Brandao PM; Colombo S; Lago M; Duarte MA. Apical third enlargement of the root canal and its relationship with the repair of periapical lesions. Eur J Dent. 2012;6(4):385-8.

62. Gambill JM; Alder M; del Rio CE. Comparison of nickel-titanium and stainless steel hand-file instrumentation using computed tomography. J Endod. 1996;22(7):369-75.

63. Connert T; Zehnder MS; Weiger R; Kühl S; Krastl G. Microguided Endodontics: Accuracy of a Miniaturized Technique for Apically Extended Access Cavity Preparation in Anterior Teeth. Journal of Endodontics;43(5):787-90.

64. Stewart JT; Lafkowitz S; Appelbaum K; Hartwell G. Distortion and Breakage of Liberator, EndoSequence, and ProFile Systems in Severely Curved Roots of Molars. Journal of Endodontics;36(4):729-31.

65. Glosson CR; Haller RH; Brent Dove S; del Rio CE. A comparison of root canal preparations using Ni-Ti hand, Ni-Ti engine-driven, and K-Flex endodontic instruments. Journal of Endodontics;21(3):146- 
66. Nevares G; de Albuquerque DS; Freire LG; Romeiro K; Fogel HM; dos Santos M, et al. Efficacy of ProTaper NEXT Compared with Reciproc in Removing Obturation Material from Severely Curved Root Canals: A Micro-Computed Tomography Study. Journal of Endodontics;42(5):803-8.

67. Neelakantan P; Khan K; Hei Ng GP; Yip CY; Zhang C; Pan Cheung GS. Does the Orifice-directed Dentin Conservation Access Design Debride Pulp Chamber and Mesial Root Canal Systems of Mandibular Molars Similar to a Traditional Access Design? Journal of Endodontics;44(2):274-9.

68. Alovisi M; Pasqualini D; Musso E; Bobbio E; Giuliano C; Mancino D, et al. Journal of Endodontics;44(4):614-20.

69. Gluskin AH, Peters CI, Wong RD Ming, Ruddle CJ. Retreatment of non-healing endodontic therapy and management of mishaps. In: Ingle JI, Bakland LK, Baumgartner C, editors. Text book of Endodontics. 6th ed. Hamilton, Ontario, USA: BC Decker; 2008. pp. 108861

70. American Association of Endodontist Glossary of Endodontic Terms. $9^{\text {th }}$ ed. Chicago: AAE; 2016. 71. WaveOne Gold Variable Taper. Digital image. Advanced Endodontics. Web. 14 February 2018. http://www.endoruddle.com/WaveOned

72. WaveOne Gold Reciprocating Motion. Digital image. Advanced Endodontics. Web. 14 February 2018. http://www.endoruddle.com/WaveOned

73. ProTaper Universal vs. NEXT center of rotation. Digital image. Dentsply Sirona. Web. 14 February 2018. https://www.dentsplysirona.com/en-us/products/endodontics/glide-pathshaping/protaper-next-files-learn-more.html

74. ProTaper Next variable tapers. Digital Image.Alibaba.com. Web. 14 February 2018. https://www.alibaba.com/product-detail/engine-use-dental-endo-niti-Rotary_60695935492.html

75. Micro-CT rendering of the MB root of True Tooth \#3. Digital Image. Dental Engineering Labratories. Web. 14 February 2018. http://dentalengineeringlab.com/wpcontent/uploads/2016/06/3-001-1-400x400.jpg 